Article

\title{
Morphological, Morphometrical and Molecular Characterization of Oscheius siddiqii Tabassum and Shahina, 2010 (Rhabditida, Rhabditidae) from India with Its Taxonomic Consequences for the Subgenus Oscheius Andrássy, 1976
}

\author{
Aashaq Hussain Bhat ${ }^{1,2} \mathbb{D}$, Swati Gautum ${ }^{3}$, Aasha Rana ${ }^{3}$, Ashok Kumar Chaubey ${ }^{3}$, Joaquín Abolafia ${ }^{4}(\mathbb{D}$ \\ and Vladimír Pưža ${ }^{5, *}$ \\ check for \\ 1 Department of Zoology, Government Degree College Uttersoo, Anantnag 192201, India; \\ aashiqhussainbhat10@gmail.com \\ 2 Experimental Biology Research Group, Institute of Biology, Faculty of Science, University of Neuchatel, \\ Rue Emile-Argand 11, 2000 Neuchatel, Switzerland \\ 3 Nematology Laboratory, Department of Zoology, Chaudhary Charan Singh University, Meerut 250004, India; \\ swatigautamswati22@gmail.com (S.G.); aasha.aasharana@ymail.com (A.R.); akc.nema@gmail.com (A.K.C.) \\ 4 Departamento de Biología Animal, Biología Vegetal y Ecología, Universidad de Jaén, Avenida de Ben Saprut \\ s/n, 23071 Jaén, Spain; abolafia@ujaen.es \\ 5 Biology Centre, Institute of Entomology, Czech Academy of Sciences, Branišovská 31, \\ 37005 České Budějovice, Czech Republic \\ * Correspondence: vpuza@seznam.cz
}

updates

Citation: Bhat, A.H.; Gautum, S.; Rana, A.; Chaubey, A.K.; Abolafia, J.; Půža, V. Morphological, Morphometrical and Molecular Characterization of Oscheius siddiqii Tabassum and Shahina, 2010 (Rhabditida, Rhabditidae) from India with Its Taxonomic Consequences for the Subgenus Oscheius Andrássy, 1976. Biology 2021, 10, 1239. https:// doi.org/10.3390/biology10121239

Academic Editor: Natraj Krishnan

Received: 18 October 2021

Accepted: 24 November 2021

Published: 27 November 2021

Publisher's Note: MDPI stays neutral with regard to jurisdictional claims in published maps and institutional affiliations.

Copyright: (c) 2021 by the authors. Licensee MDPI, Basel, Switzerland. This article is an open access article distributed under the terms and conditions of the Creative Commons Attribution (CC BY) license (https:// creativecommons.org/licenses/by/ $4.0 /)$.
Simple Summary: Due to their potential entomopathogenicity, nematodes of the genus Oscheius have been in the spotlight of the scientific interest in recent years. Unfortunately, some of these species are poorly described and have inadequate or no molecular support. This fact complicates the systematics of the group, and a revision of these species is necessary to elucidate their taxonomic status. In the present study, we provide a detailed description based on the morphological, morphometrical, and molecular characteristics of Oscheius siddiqii from Uttar Pradesh, India, including the first scanning electron microscopy (SEM) studies of the species. Furthermore, based on morphological and molecular data, the status of some Oscheius species is discussed, and several synonymisations are proposed.

Abstract: An insect parasitic nematode belonging to the genus Oscheius was recovered from the agricultural soils from the Hapur district in western Uttar Pradesh, India. Morphological studies on this species exhibited its high resemblance with two Pakistani species: Oscheius siddiqii and O. niazii. No molecular data are available for these taxa but, morphologically, both species do not differ significantly from our strains and each other. Hence, these nematodes can be considered conspecific, and the correct name for this taxon is $O$. siddiqii, the first described species. The phylogenetic analyses of the ITS-, 18S-, and the $28 \mathrm{~S}$ rDNA sequences showed that $O$. siddiqii is a sister taxon to the group formed by Oscheius microvilli, O. myriophilus, O. safricanus, and several unidentified Oscheius species. Additionally, our analyses show that based on molecular and morphological data, the species Oscheius rugaoensis and O. microvilli cannot be distinguished from O. chongmingensis and O. myriophilus, respectively, and are thus considered junior synonyms of these taxa. Furthermore, the available data are not sufficient to evaluate the status of Oscheius basothovii and O. safricanus, which are, in consequence, considered species inquirendae. These findings highlight the necessity of the proper morphological and molecular characterisation of the described Oscheius species.

Keywords: Oscheius; systematics; phylogenetic analysis 


\section{Introduction}

The genus Oscheius was proposed by Andrássy [1], with O. insectivorus (=Rhabditis insectivora Körner in Osche 1952) as type species. Sudhaus [2,3] distinguished two groups into the genus Oscheius, the Insectivorus-group, which includes species with a bursa leptoderan or pseudopeloderan and spicules with a crochet needle-shaped tip, and the Dolichura-group, which includes species with a peloderan bursa and spicules with a thin tubular tip. More recently, Abolafia and Peña-Santiago [4] categorised both the groups as subgenera, dividing them into Oscheius: Oscheius and Dolichorhabditis, respectively, according to the division proposed by Andrássy [5,6]. With respect to the subgenus Oscheius (or insectivorus-group), 23 valid species have been described at the time of writing $[4,7]$ (Supplementary Table S1).

Unfortunately, some of these species are poorly described and have inadequate or no molecular support. This fact complicates the systematics of the group, and a revision of these species is necessary to elucidate their taxonomic status. In our recent study [7], we compared an Indian population of Oscheius sp. from India and six Oscheius species described from Pakistan (Oscheius citri, O. cobbi, O. cynodonti, O. esculentus, O. punctatus, and O. sacchari). The morphological comparison and molecular analysis of the only available genetic marker for the Pakistani species, the ITS rDNA sequence, showed that these nematodes do not differ from our Indian population and from each other; hence, they can be considered synonyms, and the correct name for this taxon is the first described species, O. citri. Such kinds of studies can significantly clarify group systematics and can improve our understanding of species diversity.

The molecular taxonomy of nematodes relies on phylogenetic reconstructions that are based on three nuclear ribosomal DNA genetic markers (conserved and variable regions of the $18 \mathrm{~S}$ and $28 \mathrm{~S}$ subunits and the more variable ITS region) [8]. In some nematode groups, the $18 \mathrm{~S}$ and $28 \mathrm{~S}$ genes lack the resolution that is required to distinguish between these closely-related lineages [9]. The quickly evolving internal transcribed spacer (ITS) region may display intrapopulation, or even individual variability [10,11], which could complicate its use in systematics [12]. Mitochondrial genes thus represent a viable option in nematode systematics [12]. Unfortunately, so far, no mitochondrial gene sequences are available for Oscheius nematodes, with the only exception being Oscheius onirici, which has several published sequences of the cytochrome oxidase I (COI) gene available in the NCBI GenBank database [13,14].

During the course of the nematological sampling survey in the Hapur district of western Uttar Pradesh, India, two Oscheius populations, labelled CS42 and CS43, were isolated from agricultural soil samples using the Galleria trap method [15] and were later morphologically identified as O. siddiqii Tabassum \& Shahina, 2010.

Oscheius siddiqii was first described from soil samples taken from around the roots of rose (Rosa damascena L.) in Karachi, Sindh, Pakistan [16]. This species was previously described based on morphological and morphometric studies alone. In the present study, a detailed description based on the morphological, morphometrical, and molecular (small subunit, large subunit, and internal transcribed spacer (ITS1-5.8S-ITS2) rDNA gene sequences) characteristics of $O$. siddiqii from Uttar Pradesh, India, is provided, including the first scanning electron microscopy (SEM) studies of the species. We also provide the first COI sequences of $O$. siddiqii and several others Oscheius species. Furthermore, based on morphological and molecular data, the status of some Oscheius species is discussed.

\section{Materials and Methods}

\subsection{Nematode Source}

Twenty soil samples were collected in different agricultural fields of the Brijghat area of the Hapur district $\left(28^{\circ} 47^{\prime} \mathrm{N}, 78^{\circ} 4^{\prime} \mathrm{E}\right.$ and elevation of $219 \mathrm{~m}$ above sea level) in western Uttar Pradesh, India, in February 2018. The predominant climate in these areas is semi-arid and moderate to tropical monsoon (humid subtropical). Each sample had $1.5 \mathrm{~kg}$ of soil, which was made up of five soil subsamples collected at five sites within each field (one 
sample from each corner of the field and one from the centre of the field). Samples were collected at a 15-20 cm depth around the rhizosphere of crop plants [17]. These samples were tested for the presence of nematodes using the Galleria soil baiting technique [15]. Two soil samples taken from sugarcane fields (Saccharum officinarum L.) and cucumber (Cucumis sativus L.) cultivars were found to be positive for the presence of nematodes and were labelled as CS42 and CS43. The pH of the soil samples ranged from 9.6-10.0. The cadavers of Galleria mellonella L. (Lepidoptera, Pyralidae) from the soil baits were transferred to white traps after proper washing with double distilled water and sterilization with $0.1 \%$ $\mathrm{NaOCl}$ [12]. The nematodes that emerged from the white trap within 6-10 days were collected. The nematode cultures were kept in $250 \mathrm{~mL}$ flasks in the Bio-Oxygen Demand incubators at a temperature of $15^{\circ} \mathrm{C}$.

Slides and live specimens are also deposited at CCS University Meerut, University of Jaén, and the Institute of Entomology Czech Republic, respectively. Scanning electron microscopy and light microscopy images were taken at the University of Jaén, while the molecular studies were conducted at CCS University Meerut and at the Institute of Entomology, Czech Republic.

\subsection{Morphological and Morphometrical Characterization}

Prior to the light microscopic studies and morphometry analyses, the nematodes were propagated using the last instar larvae of G. mellonella by injecting 10 greater wax moth larvae with approximately 2000 surface-sterilized dauer larvae in sterilized Petri dishes using a $1 \mathrm{~mL}$ insulin syringe. The larvae died within 48-72 h [7]. Adult generations (females and males) and 3rd stage juveniles were isolated from the white trap within 7-10 days [18]. These were killed with hot water at $60^{\circ} \mathrm{C}$ [19], fixed in TAF $(7 \mathrm{~mL}$ formalin,

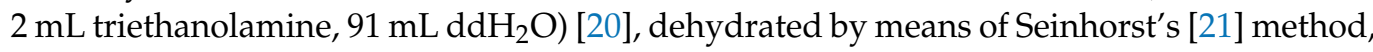
and processed to glycerine [22]. The nematodes were mounted in a small drop of glycerine on permanent glass slides and were sealed with an extra amount of paraffin wax to prevent the flattening of the nematodes [23]. The observations and measurements of 136 specimens were taken using the Nikon DS-L1 image acquisition software mounted on a phase-contrast microscope (Nikon Eclipse 50i) in $\mu \mathrm{m}$ (Tables 1 and 2). A Nikon Eclipse 80i (Nikon, Tokyo, Japan) light microscope with differential interference contrast optics and a Nikon Digital Sight DS-U1 camera were used to photograph the best-preserved nematode specimens. Adobe ${ }^{\circledR}$ Photoshop ${ }^{\circledR}$ CS was used to process the micrographs. Nematode species were identified based on morphological and morphometric features using the keys described by Abolafia and Peña-Santiago [4]. The morphological and morphometrical traits used to characterise the species are given in Tables 1 and 2, and the morphometrical data were analysed in SPSS software to calculate different central tendency measures (Table 1).

Table 1. Morphometric data of Oscheius siddiqii Tabassum and Shahina, 2010 (isolate CS42). All measurements are in $\mu \mathrm{m}$ (except $n$, ratio and percentage) and in the form of mean $\pm \mathrm{SD}$ (range).

\begin{tabular}{|c|c|c|c|}
\hline Characters & Female & Male & J3 Juvenile \\
\hline$n$ & 20 & 20 & 20 \\
\hline Body length (L) & $1465 \pm 135$ (1204-1697) & $1135 \pm 126(916-1441)$ & $534 \pm 21(502-574)$ \\
\hline$a(\mathrm{~L} / \mathrm{MBD})$ & $16.7 \pm 1.2(14.2-19.4)$ & $24 \pm 4.7(14.7-25.8)$ & $21 \pm 1.0(19.3-22.7)$ \\
\hline$b(\mathrm{~L} / \mathrm{NL})$ & $7.7 \pm 0.9(6.1-8.9)$ & $6.7 \pm 0.6(5.3-7.7)$ & $4.3 \pm 0.3(3.7-4.9)$ \\
\hline$c(\mathrm{~L} / \mathrm{T})$ & $10.4 \pm 1.5(7.8-15.4)$ & $28 \pm 3.1(20.1-32.9)$ & $7.4 \pm 0.6(7.0-8.2)$ \\
\hline$c^{\prime}(\mathrm{T} / \mathrm{ABW})$ & $4.8 \pm 0.8(3.5-6.3)$ & $1.8 \pm 0.2(1.5-2.5)$ & $6.0 \pm 0.7(4.9-7.2)$ \\
\hline$V \%(\mathrm{AV} / \mathrm{L} \times 100)$ & $50 \pm 3.1(45-57)$ & - & - \\
\hline Lip region width & $7.1 \pm 0.6(6-8)$ & $7.1 \pm 0.8(6-9)$ & $4.1 \pm 0.8(3-6)$ \\
\hline Stoma length & $17.1 \pm 1.1(15-20)$ & $17.1 \pm 2.1(13-20)$ & $13.9 \pm 1.6(10-17)$ \\
\hline Stomatal tube width & $3.1 \pm 0.3(2.5-3.8)$ & $4.0 \pm 0.7(3.2-5.4)$ & - \\
\hline Procorpus length & $64 \pm 3.4(58-69)$ & $58 \pm 5.6(47-66)$ & $42 \pm 2.6(37-46)$ \\
\hline Metacorpus length & $38 \pm 2.9(32-42)$ & $33 \pm 1.6(31-36)$ & $21 \pm 2.1(18-23)$ \\
\hline Isthmus length & $64 \pm 3.4(58-69)$ & $45 \pm 3.3 .6(37-50)$ & $29 \pm 2.2(37-46)$ \\
\hline Bulb length & $35 \pm 3.5(24-34)$ & $31 \pm 3.0(27-37)$ & $21 \pm 2.1(18-23)$ \\
\hline Pharynx length & $183 \pm 6.6(169-198)$ & $165 \pm 7.3(139-173)$ & $106 \pm 7.5(95-127)$ \\
\hline Nerve ring-ant. end (NR) & $153 \pm 10.6(133-175)$ & $138 \pm 10.6(119-178)$ & $73 \pm 6.9(61-81)$ \\
\hline Excretory pore- ant. end (EP) & $191 \pm 17(171-224)$ & $189 \pm 22.4(162-212)$ & $120 \pm 6.6(100-132)$ \\
\hline
\end{tabular}


Table 1. Cont.

\begin{tabular}{|c|c|c|c|}
\hline Characters & Female & Male & J3 Juvenile \\
\hline Deirid-ant. end & $163 \pm 13.0(141-196)$ & $135 \pm 13.6(106-156)$ & - \\
\hline Neck length (stoma + pharynx, NL) & $221 \pm 8.0(205-239)$ & $183 \pm 7.2(172-192)$ & $125 \pm 4.8(116-136)$ \\
\hline Body width at neck base & $54 \pm 6.3(42-66)$ & $42 \pm 3.8(36-51)$ & $28 \pm 2.1(25-31)$ \\
\hline Mid-body diameter (MBD) & $94 \pm 7.5(81-114)$ & $49 \pm 7.7(38-64)$ & $25 \pm 1.4(23-28)$ \\
\hline Uterus or testis length & $69 \pm 15.5(53-87)$ & $557 \pm 36(464-596)$ & - \\
\hline Anterior spermatheca length & $44 \pm 8.0(31-63)$ & - & - \\
\hline Anterior genital branch & $313 \pm 50(213-392)$ & - & - \\
\hline Posterior spermatheca length & $39 \pm 7.4(31-54)$ & - & - \\
\hline Posterior genital branch & $257 \pm 40(202-329)$ & - & - \\
\hline Vagina length & $24 \pm 4.1(18-31)$ & - & - \\
\hline Vulva-ant. end (AV) & $732 \pm 57(610-860)$ & - & - \\
\hline Rectum length & $70 \pm 9.8(57-81)$ & - & $31 \pm 2.6(26-39)$ \\
\hline Anal body diam. (ABD) & $32 \pm 2.9(26-41)$ & $21 \pm 2.9(19-26)$ & $12.8 \pm 1.3(11-16)$ \\
\hline Tail length $(\mathrm{T})$ & $147 \pm 20(123-169)$ & $41 \pm 3.3(38-48)$ & $76 \pm 10.1(59-98)$ \\
\hline Phasmid to anus distance & $42 \pm 6.3(33-57)$ & $24 \pm 1.2(21-26)$ & - \\
\hline Spicule length (SL) & - & $44 \pm 5.1(39-53)$ & - \\
\hline Gubernaculum length (GL) & - & $21 \pm 3.1(22-26)$ & - \\
\hline Hyaline part of tail $(\mathrm{H})$ & - & - & $41 \pm 6.3(36-49)$ \\
\hline
\end{tabular}

$-=$ characters absent or not measured.

Table 2. Morphometrics of Oscheius siddiqii Tabassum and Shahina, 2010 (isolation CS43). All measurements are in $\mu \mathrm{m}$ (except $n$, ratio and percentage) and in the form of mean \pm SD (range).

\begin{tabular}{|c|c|c|c|}
\hline Characters & Female & Male & J3 Juvenile \\
\hline$n$ & 20 & 20 & 20 \\
\hline Body length (L) & $1439 \pm 139(1121-1586)$ & $1021 \pm 77(920-1180)$ & $551 \pm 28(500-598)$ \\
\hline$a(\mathrm{~L} / \mathrm{MBD})$ & $16.9 \pm 1.8(13.6-19.2)$ & $23 \pm 2.1(19.9-26.7)$ & $19.9 \pm 1.3(17.7-22.4)$ \\
\hline$b(\mathrm{~L} / \mathrm{NL})$ & $72 \pm 0.9(5.6-8.2)$ & $6.0 \pm 0.6(5.1-7.2)$ & $4.2 \pm 0.2(3.8-4.8)$ \\
\hline$c(\mathrm{~L} / \mathrm{T})$ & $8.3 \pm 0.8(6.3-9.5)$ & $25 \pm 2.5(19.7-30.5)$ & $6.9 \pm 0.7(5.7-8.3)$ \\
\hline$c^{\prime}(\mathrm{T} / \mathrm{ABD})$ & $6.6 \pm 0.7(5.2-7.5)$ & $1.8 \pm 0.3(1.4-2.5)$ & $5.9 \pm 0.7(4.8-7.7)$ \\
\hline$V \%(\mathrm{AV} / \mathrm{L} \times 100)$ & $52 \pm 11.2(48-61)$ & - & - \\
\hline Lip region width & $6.1 \pm 0.6(6-7)$ & $5.8 \pm 0.8(5-7)$ & $3.5 \pm 0.6(2-5)$ \\
\hline Stoma length & $15.9 \pm 1.6(13-19)$ & $14.9 \pm 1.6(13-20)$ & $13.8 \pm 2.0(10-17)$ \\
\hline Stomatal tube width & $3.2 \pm 0.8(2-5)$ & $3.1 \pm 0.5(2-4)$ & - \\
\hline Procorpus length & $61 \pm 6.0(53-68)$ & $54 \pm 6.1(45-69)$ & $41 \pm 1.4(37-48)$ \\
\hline Metacorpus length & $36 \pm 3.3(31-41)$ & $32 \pm 3.4(27-39)$ & $24 \pm 1.6(21-27)$ \\
\hline Isthmus length & $50 \pm 2.3(46-53)$ & $38 \pm 5.0(44-48)$ & $33 \pm 3.1(30-41)$ \\
\hline Bulb length & $30 \pm 2.0(28-34)$ & $29 \pm 3.0(24-35)$ & $18.9 \pm 1.7(17-24)$ \\
\hline Pharynx length & $177 \pm 4.7(169-183)$ & $153 \pm 9.8(139-173)$ & $117 \pm 4.9(108-129)$ \\
\hline Nerve ring-ant. end (NR) & $154 \pm 12.9(138-181)$ & $149 \pm 8.0(130-162)$ & $82 \pm 4.9(70-89)$ \\
\hline Excretory pore-ant. end (EP) & $197 \pm 13(172-216)$ & $195 \pm 14.1(162-220)$ & $118 \pm 5.6(108-129)$ \\
\hline Deirid-ant. end & $159 \pm 10.0(139-170)$ & $133 \pm 8.4(118-149)$ & - \\
\hline Neck length (stoma + pharynx, NL) & $196 \pm 4.4(189-201)$ & $171 \pm 10.1(158-190)$ & $131 \pm 4.7(123-143)$ \\
\hline Body width at neck base & $34 \pm 2.7(30-38)$ & $35 \pm 4.8(26-42)$ & $27 \pm 2.6(23-34)$ \\
\hline Mid-body diameter (MBD) & $81 \pm 12(72-98)$ & $44 \pm 5.6(38-58)$ & $28 \pm 1.4(25-30)$ \\
\hline Uterus or testis length & $74.1 \pm 15.3(56-98)$ & $539 \pm 40(545-590)$ & - \\
\hline Anterior spermatheca length & $38 \pm 5.1(32-49)$ & - & - \\
\hline Anterior genital branch & $275 \pm 41(210-343)$ & - & - \\
\hline Posterior spermatheca length & $37 \pm 5.0(28-44)$ & - & - \\
\hline Posterior genital branch & $240 \pm 30(204-290)$ & - & - \\
\hline Vagina length & $23 \pm 2.6(19-28)$ & - & - \\
\hline Body width at vulva & $77 \pm 11.2(59-109)$ & - & - \\
\hline Vulva-ant. end (AV) & $741 \pm 74(568-829)$ & - & - \\
\hline Rectum length & $67 \pm 4.6(61-75)$ & - & $35 \pm 2.8(28-39)$ \\
\hline Anal body diam. (ABD) & $27 \pm 3.0(22-34)$ & $23 \pm 1.9(20-27)$ & $14 \pm 1.5(11-16)$ \\
\hline Tail length (T) & $173 \pm 6.2(154-180)$ & $42 \pm 4.7(36-49)$ & $81 \pm 7.7(70-96)$ \\
\hline Phasmid to anus distance & $39 \pm 4.8(34-50)$ & $22 \pm 3.6(17-26)$ & - \\
\hline Spicule length (SL) & - & $51 \pm 4.9(37-55)$ & - \\
\hline Gubernaculum length (GL) & - & $25 \pm 2.7(21-26)$ & - \\
\hline Hyaline part of tail $(\mathrm{H})$ & - & - & $42 \pm 3.2(36-47)$ \\
\hline
\end{tabular}




\subsection{Scanning Electron Microscopy}

For the scanning electron microscopy, male and female specimens kept in glycerol were chosen for observation according to the protocol proposed by Abolafia [24]. The nematodes were hydrated in $\mathrm{dH}_{2} \mathrm{O}$, dehydrated in a graded ethanol-acetone series, critical point dried with dry ice, mounted on SEM stubs with copper tape, and coated with gold in a sputter coater. Specimens were observed, and the microphotographs for ach sample were captured with a Zeiss Merlin microscope ( $5 \mathrm{kV}$ ) (Zeiss, Oberkochen, Germany). All of the light and scanning electron microscopy images were submitted to the $\mathrm{X}$ public database.

\subsection{Molecular Analyses}

DNA was isolated from the females and from the bulk of the dauer larvae $(n>500)$ (IJs). Individual females were placed in sterilized microcentrifuge tubes $(250 \mu \mathrm{L})$ containing $10 \mu \mathrm{L}$ of extraction buffer $\left(8.85 \mu \mathrm{L}\right.$ of $\mathrm{dd}_{2} \mathrm{O}, 1 \mu \mathrm{L}$ of $10 \times$ PCR buffer, $0.1 \mu \mathrm{L}$ of $1 \%$ Tween, and $0.05 \mu \mathrm{L}$ of proteinase $\mathrm{K}$ ). Samples were frozen at $-20{ }^{\circ} \mathrm{C}$ for $20 \mathrm{~min}$ and were then kept at $65^{\circ} \mathrm{C}$ for $1 \mathrm{~h}$ and finally at $95^{\circ} \mathrm{C}$ for $10 \mathrm{~min}$. The lysates were cooled on ice and centrifuged ( $2 \mathrm{~min}, 9000 \mathrm{~g}$ ), and $1 \mu \mathrm{L}$ of supernatant was used for PCR [18]. The DNA from the pool of IJs was isolated using the Qiagen Blood and Tissue Analysis Kit (Hilden, Germany) according to the instructions of the manufacturer. For each locus that was amplified (see further), the DNA from five females and from the bulk of dauer larvae were used. A section of the rDNA comprising the internally transcribed spacer regions (ITS1-5.8S-ITS2) was amplified using the following $18 \mathrm{~S}$ primers: $5^{\prime}$ TTGATTACGTCCCTGCCCTTT- $3^{\prime}$ (forward) and 28S: $5^{\prime}$-TTTCACTCGCCGTTACTAAGG$3^{\prime}$ (reverse) [25]. The other section comprising the D2-D3 expansion domains of the 28S rDNA gene (large subunit, LSU) was amplified using the following D2F primers: $5^{\prime}-$ CCTTAGTAACGGCGAGTGAAA-3' (forward) and 536: 5'-CAGCTATCCTGAGGAAAC-3' (reverse) [26]; a region comprising $18 \mathrm{~S}$ rDNA (small subunit, SSU) was determined using the following 18S-F primer pairs: 5'-GATACCGCCCTAGTTCTGACC-3' and 18S-R: $5^{\prime}$ ACCAACTAAGAACGGCCATG-3' [27] and G18S4: $5^{\prime}$-GCTTGTCTCAAAGATTAAGCC-3' and 18P: 5'-TGATCCWMCRGCAGGTTCAC-3' [28].

The PCR master mix included $7.25 \mu \mathrm{L}$ of $\mathrm{ddH}_{2} \mathrm{O}, 1.25 \mu \mathrm{L}$ of $10 \times$ PCR buffer, $1 \mu \mathrm{L}$ of dNTPs, $0.75 \mu \mathrm{L}$ of each forward and reverse primers, $0.1 \mu \mathrm{L}$ of DNA polymerase, and $1 \mu \mathrm{L}$ of DNA-extract. The PCR profiles were used as follows for ITS: 1 cycle of $94{ }^{\circ} \mathrm{C}$ for $7 \mathrm{~min}$ followed by 35 cycles of $94{ }^{\circ} \mathrm{C}$ for $60 \mathrm{~s}, 50{ }^{\circ} \mathrm{C}$ for $60 \mathrm{~s}, 72{ }^{\circ} \mathrm{C}$ for $60 \mathrm{~s}$, and a final extension at $72{ }^{\circ} \mathrm{C}$ for $7 \mathrm{~min}$ [26]; for $28 \mathrm{~S}$ rDNA: 1 cycle of $94{ }^{\circ} \mathrm{C}$ for $7 \mathrm{~min}$ followed by 35 cycles of $94{ }^{\circ} \mathrm{C}$ for $60 \mathrm{~s}, 55^{\circ} \mathrm{C}$ for $60 \mathrm{~s}, 72{ }^{\circ} \mathrm{C}$ for $60 \mathrm{~s}$, and a final extension at $72{ }^{\circ} \mathrm{C}$ for $10 \mathrm{~min}$ [29]; for $18 \mathrm{~S}$ rDNA: 1 cycle of $94^{\circ} \mathrm{C}$ for 5 min followed by 37 cycles of $94{ }^{\circ} \mathrm{C}$ for $60 \mathrm{~s}, 55{ }^{\circ} \mathrm{C}$ for $90 \mathrm{~s}, 72{ }^{\circ} \mathrm{C}$ for $2 \mathrm{~min}$, and a final extension at $72{ }^{\circ} \mathrm{C}$ for $10 \mathrm{~min}$ [30]. After PCR, $2 \mu \mathrm{L}$ of PCR product was electrophoresed in a 1\% TAE-buffered agarose gel stained with ethidium bromide ( $20 \mu \mathrm{L}$ ETB per $100 \mathrm{~mL}$ of gel) for $45 \mathrm{~min}$ at $120 \mathrm{~V}$ [31]. For each locus, PCR products from five females were sequenced by Eurofins Genomics (Ebersberg, Germany) and PCR-product from a bulk of dauer juveniles was sequenced by Bioserve PVT Ltd. (Hyderabad, India). No variation was detected in any of the products for each locus except for the ITS region of the strain CS42, and one sequence for each fragment was deposited in GenBank under accession numbers MH837093 (ITS sequence, strain CS43, the amplicon length $939 \mathrm{bp}$ ), MH819729 (28S sequence, CS42, amplicon length $885 \mathrm{bp}$ ), MT835468 (18S sequence, strain CS42, amplicon length $1571 \mathrm{bp}$ ), and MH845237 (28S sequence, CS43, amplicon length $885 \mathrm{bp}$ ). Due to the presence of variability in the ITS region of the strain CS42, an additional 15 individuals were sequenced for this marker. The two sequence variants were deposited under the accession numbers MH837095 and MT835467 (ITS sequences, strain CS42, and amplicon lengths $1010 \mathrm{bp}$ and $990 \mathrm{bp}$ ).

\subsection{Sequence Alignment and Phylogenetic Analyses}

The sequences were edited and compared with other sequences deposited in the GenBank NCBI database using the BLAST tool [32]. An alignment of our sequences with 
those of other Oscheius species was performed for each amplified locus (ITS, SSU and LSU) using the default ClustalW parameters in MEGA 7.0 [33] and was optimized manually in BioEdit [34]. The final alignment lengths were 904 bp (ITS), 476 bp (D2D3) and 1565 bp (SSU). Pairwise distances were computed using MEGA 7.0 [33] in order to compare the ITS rDNA locus of the selected Oscheius species from the "insectivorus" group.

The phylogenetic reconstruction was performed from the datasets using the Bayesian inference (BI). All of the characters were treated as being equally weighted. Heterorhabditis bacteriophora Poinar, 1976; H. zealandica Poinar, 1990; and H. downesi Stock, Griffin \& Burnell, 2002; were used as outgroup taxa. Bayesian analyses were performed in MrBayes 3.2.7 [35]. The best fit model was identified as the GTR + G model test using the MrModeltest 2.0 program [36]. Metropolis-coupled Markov chains Monte Carlo (MCMCMC) generations were run for $1 \times 10^{7}$ cycles, and 1 tree was retained every 1000 generations. The Bayesian trees were visualized using the Mesquite program [37].

\subsection{Analysis of the Cytochrome Oxidase I Gene}

For the analysis, Ocheius siddiqii CS42 and five other Oscheius species or strains from our collection (Table 3) were used. The DNA was isolated from single females, and the cytochrome oxidase subunit I (COI) gene was amplified using the universal primers LCO-1490 (5'-GGTCAACAAATCATAAAGATATTGG-3') (forward) and HCO-2198 (5'TAAACTTCAGGGTGACCAAAAAATCA-3') (reverse) [38] with the following PCR profile: 1 cycle of $94{ }^{\circ} \mathrm{C}$ for $2 \mathrm{~min}$ followed by 37 cycles of $94{ }^{\circ} \mathrm{C}$ for $30 \mathrm{~s}, 5{ }^{\circ} \mathrm{C}$ for $45 \mathrm{~s}, 72{ }^{\circ} \mathrm{C}$ for $2 \mathrm{~min}$, and a final extension at $72{ }^{\circ} \mathrm{C}$ for $2 \mathrm{~min}$. Sequences were deposited in GenBank under accession numbers OK142792-OK142797 (Table 3).

Table 3. Pairwise distances of the COI gene among selected Oscheius species. The values above diagonal represent percent similarities, and the values below diagonal represent numbers of character differences.

\begin{tabular}{|c|c|c|c|c|c|c|c|c|c|c|c|c|}
\hline S. No. & COI Region & 1 & 2 & 3 & 4 & 5 & 6 & 7 & 8 & 9 & 10 & 11 \\
\hline 1 & OK142792 O. siddiqii CS42 & & 92.9 & 92.9 & 91.0 & 97.3 & 89.1 & 89.4 & 88.5 & 89.9 & 88.1 & 88.1 \\
\hline 2 & OK142795 O. myriophilus $1 \mathrm{~b}$ & 44 & & 99.9 & 89.7 & 92.5 & 89.2 & 89.8 & 89.7 & 90.2 & 88.7 & 88.7 \\
\hline 3 & OK142794 O. myriophilus JU1386 & 44 & 1 & & 89.6 & 92.6 & 89.4 & 89.4 & 89.2 & 89.7 & 88.3 & 88.3 \\
\hline 4 & OK142796 O. citri WGN & 56 & 64 & 65 & & 90.4 & 86.8 & 89.4 & 88.1 & 88.9 & 87.3 & 87.3 \\
\hline 5 & OK142793 O. chongmingensis & 17 & 51 & 57 & 60 & & 88.9 & 89.2 & 88.4 & 89.5 & 88.1 & 88.1 \\
\hline 6 & OK142797 O. guentheri & 68 & 73 & 81 & 82 & 85 & & 88.0 & 87.4 & 88.3 & 87.4 & 87.4 \\
\hline 7 & MF196100.1 O. onirici 16-33834 & 46 & 50 & 55 & 46 & 56 & 62 & & 99.2 & 99.7 & 98.6 & 98.6 \\
\hline 8 & MK754223.1 O. onirici N6691 & 48 & 49 & 54 & 50 & 58 & 63 & 5 & & 99.7 & 98.4 & 98.4 \\
\hline 9 & KY582595.1 O. onirici Wisconsin 6 & 40 & 44 & 49 & 44 & 50 & 56 & 2 & 2 & & 98.3 & 98.3 \\
\hline 10 & LN613269.1 O. onirici FDL-2014 & 44 & 48 & 53 & 47 & 54 & 57 & 8 & 10 & 10 & & 100 \\
\hline 11 & LN613268.1 O. onirici FDL-2014 & 44 & 48 & 53 & 47 & 54 & 57 & 8 & 10 & 10 & 0 & \\
\hline
\end{tabular}

\section{Results}

Oscheius siddiqii Tabassum and Shahina, 2010 (Figures 1-4, Tables 1 and 2).

\subsection{Description of Oscheius (Oscheius) siddiqii Tabassum \& Shahina, 2010}

Female $(n=20)$ : Body larger than in males; $1.10-1.70 \mathrm{~mm}$ long; straight to slightly arcuate. Cuticle moderately transversely annulated. Lateral fields consisting of six distinct longitudinal incisures and other two sublateral poorly marked incisures. Lip region bearing six separate lips, with six inner long acute labial papillae and four outer short acute cephalic papillae in total; primary axils deeper than secondary axils. Amphidial apertures are porelike and ovoid. Stoma rhabditoid type; 4.1-5.9 times longer than wide and 3.4-6.2 times the lip region width: conspicuous cheilostom, poorly cuticularised rounded rhabdia; gymnostom and pro-mesostegostom cuticularised with straight tubular rhabdia; short metastegostom with well-developed glottoid apparatus; short telostegostom with rounded cuticularised rhabdia. Conspicuous deirids present at $81-93 \%$ of neck length. Pharynx differentiated into cylindrical procorpus with swollen and subcylindrical metacorpus that 
is about twice as long as it is wide; long isthmus that is narrower than the procorpus; ovoid basal bulb with conspicuous valvular apparatus. Nerve ring encircling the isthmus at $70-89 \%$ of the neck length. Excretory pore at basal bulb or posterior that is located at $100-110 \%$ of the neck length. Conspicuous hemizonid just above excretory pore at the level of the basal bulb. Intestine with the cardiac region with thinner walls.

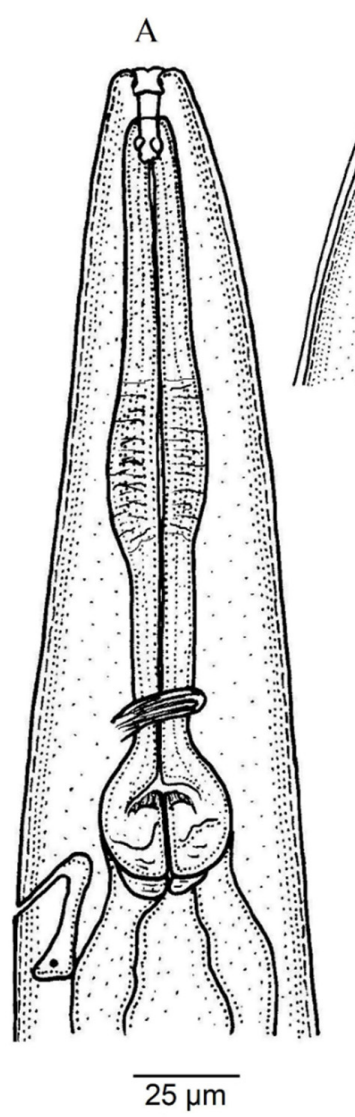

$\mathrm{G}$

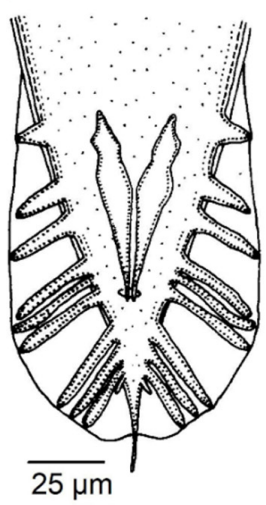

$\mathrm{B}$

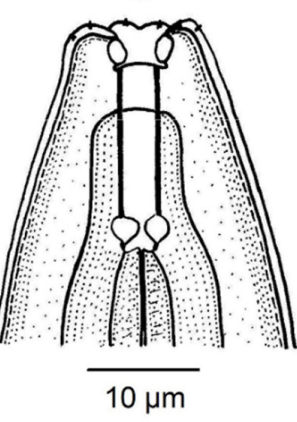

$\mathrm{F}$

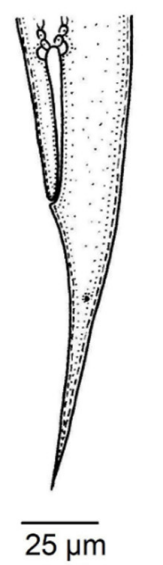

$\mathrm{H}$

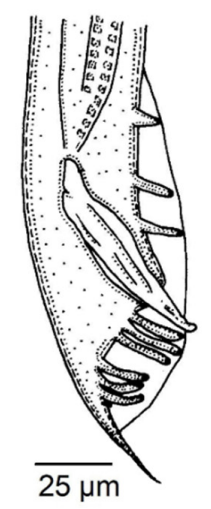

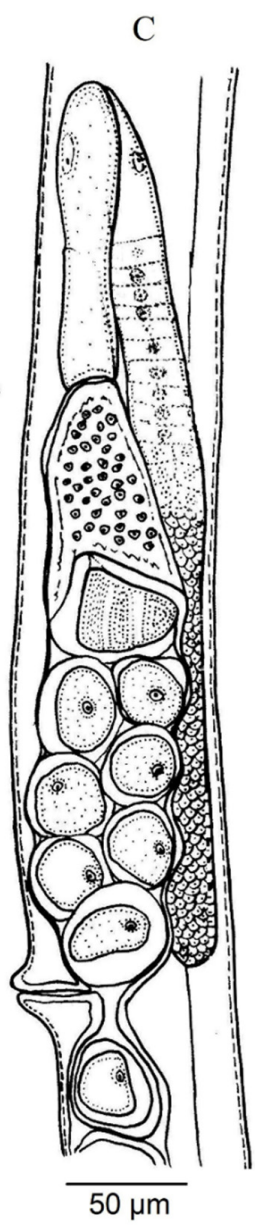

I

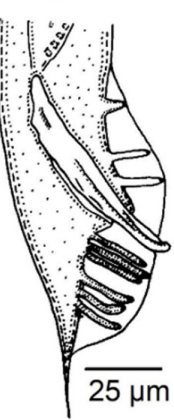

$\mathrm{J}$
D E
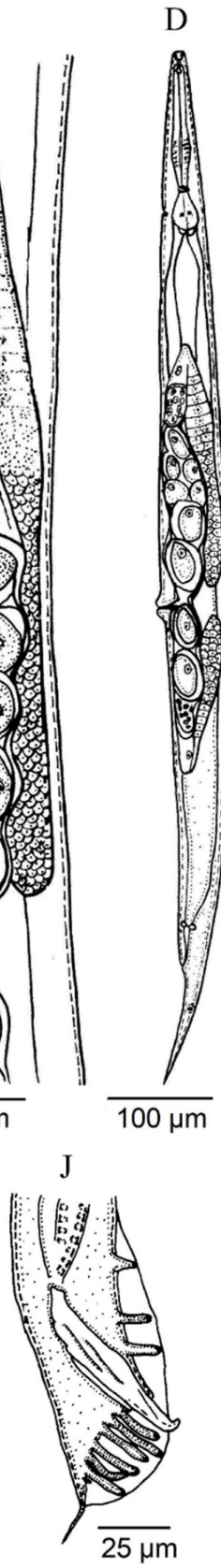

E

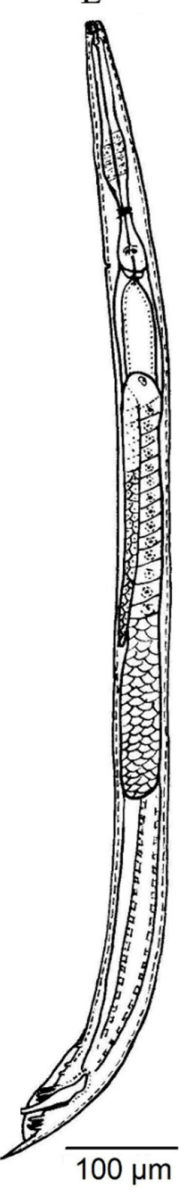

$\mathrm{K}$

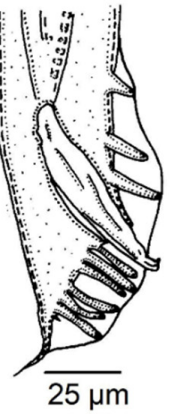

Figure 1. Oscheius siddiqii Tabassum and Shahina, 2010 (line drawing). (A): neck; (B): anterior end; (C): female reproductive system; (D): entire female; (E): entire male; (F): female posterior end; (G): male posterior end at ventral view; (H-K): male posterior end at lateral view showing variations in spicules.

Didelphic and amphidelphic reproductive system; well-developed ovaries that are dorsally reflexed and that extend beyond the vulva; anterior and posterior ovaries on the same side of the intestine, with the anterior one larger than posterior one; oviducts with spermathecae are ovoid and filled with sperm and connected to dilated ovaries; long uteri 
that are divided in two parts are only observed in young females and comprise one distal tubular part and other proximal swollen part with thinner walls; uterine eggs in different embryonation stages compacted in uteri ranging in number from 6-24 and measuring 26-57 $\times 27-32 \mu \mathrm{m}$; vagina straight or slightly arcuate, ventral with lateral epiptygmata. Distinct rectum distinct that is 1.9-2.8 times anal body width, with three unicellular glands at its junction with the intestine. Large anus that is directed posteriorly. Straight, conoid tail with acute terminus. Distinct, pore like, phasmids located at $50-80 \%$ of tail length.

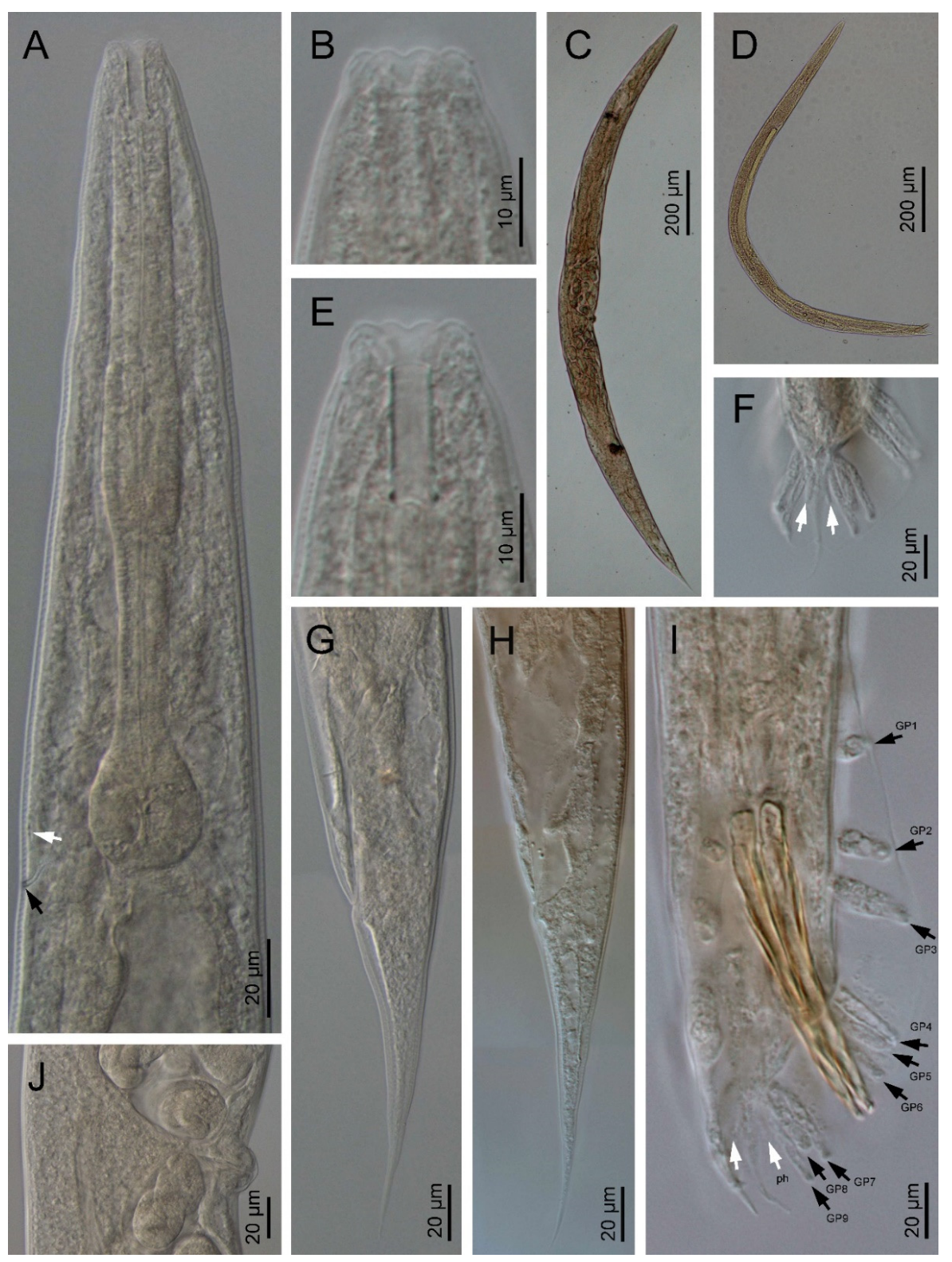

Figure 2. Oscheius siddiqii Tabassum and Shahina, 2010 (light microscopy). (A): Neck (black arrow pointing the excretory pore and white arrow pointing the hemizonid); (B,E): anterior end; $(\mathbf{C})$ : entire female; (D): entire male; (F): male tail end (arrows pointing phasmids); $(\mathbf{G}, \mathbf{H})$ : female posterior end (arrow pointing the phasmid); (I): male posterior end (black arrows pointing genital papillae (GP), white arrows pointing phasmids (ph)); (J): female vulva.

Male $(n=20)$ : Body 0.92-1.44 mm long; "J"-shaped after heat killing with general morphology similar to female except for smaller size and arcuate posterior body. Monorchic reproductive system with testis ventrally reflexed anteriorly on the left side of intestine. Vas deferens are broad and light tubes filled with sperm and lack demarcation of seminal 
vesicle. Ejaculatory glands not present. Tail with conoid anterior part that is flanked by the bursa, and short and thin posterior filiform section that is located outside of the bursa and that is sometimes inconspicuous under LM. Bursa leptoderan with nine pairs of genital papillae $(1+1+1 / 3+3+$ ph): three pairs pre-cloacal (GP1-GP3) and six pairs post-cloacal, with three pairs at mid tail length (GP4-GP6) and three pairs (GP7-GP9) at the terminal length; GP1, GP2, and GP3 are spaced apart; space between GP1 and GP2 is greater than the space between GP2 and GP3. Phasmids are easily observed and are located posterior to GP9 at 55-65\% of the tail length. Long spicules that are broad and arcuate as well as larger than the gubernaculum and a manubrium that is ventrally bent and conoid to rounded; short calamus and lamina that are slightly ventrally curved with dorsal hump that is variable in size; long ventral velum and hooked tip. Gubernaculum with manubrium-corpus that is almost straight; well-developed crura with acute tip that is at $37-49 \%$ of the spicule length.
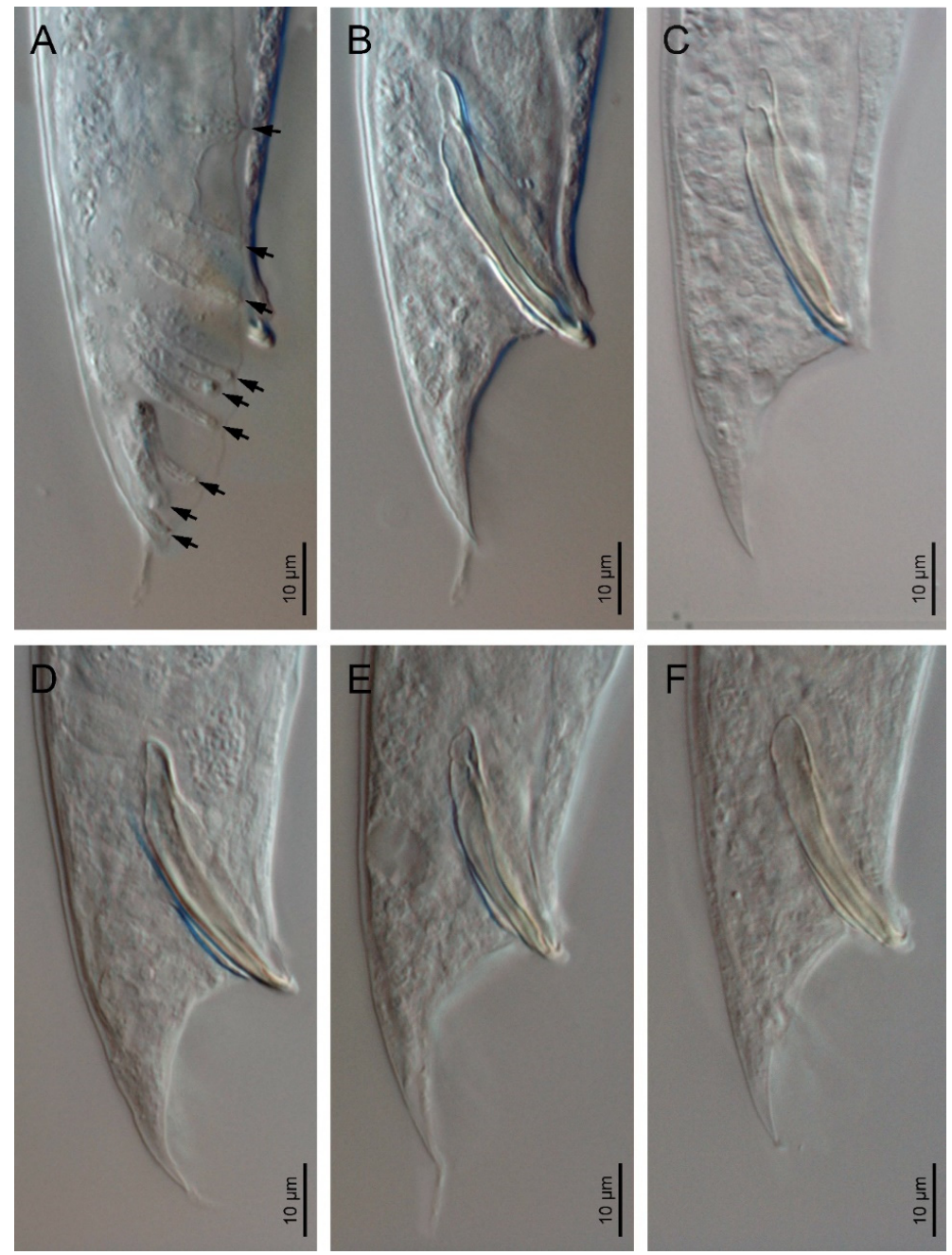

Figure 3. Oscheius siddiqii Tabassum and Shahina, 2010 (light microscopy). (A): Male posterior end at ventral view showing pattern of the genital papillae; (B-F): male posterior end at lateral view showing variations in spicules.

Third stage juvenile (J3) $(n=20)$ : Robust body that is $0.50-0.60 \mathrm{~mm}$ long with straight or slightly curved at posterior end. Cuticle is almost smooth, with a lip region similar to adult specimens. Narrow stoma that 2.1-3.0 times as narrow as the lip region is wide. Pharynx clearly visible and differentiated into the three rhabditoid parts. Nerve ring surrounding the isthmus that is about $60-74 \%$ of the neck length. Excretory pore at or just posterior to basal bulb. Obscure deirid. Reduced cardia reduced that is surrounded 
by intestinal tissue. Rectum longer than anal body width. Anus prominent. Tail conoid; spicate with fine hair-like terminus without mucro with terminal hyaline part that is $42-66 \%$ of the tail length.
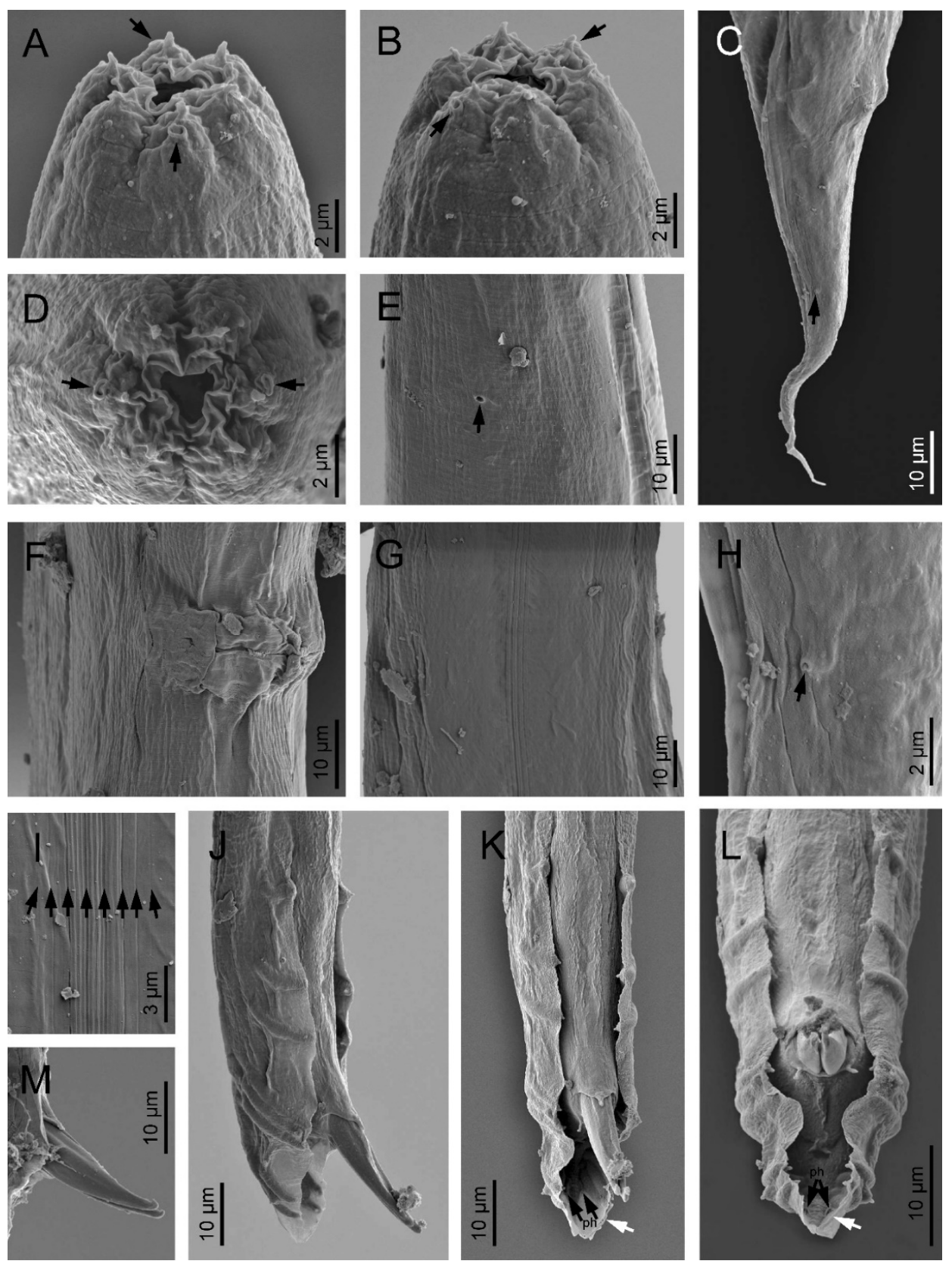

Figure 4. Oscheius siddiqii Tabassum and Shahina, 2010 (scanning electron microscopy). (A,B,D): Lip region in lateral (A,B) and frontal (D) views (arrows pointing the amphids); (C): female posterior end (arrow pointing the phasmid); (E): excretory pore (arrow); (F,G,H): vulva; (I): lateral field (arrows pointing the longitudinal incisures); $(\mathbf{J}, \mathbf{K}, \mathbf{L})$ : male posterior end in right lateral, subventral, and ventral views, respectively (black arrows pointing the phasmids (ph), white arrow pointing the filiform part of tail); (M): spicule tips.

\subsection{Molecular Characterization}

Oscheius siddiqii is characterized by sequences of the ITS region, the SSU and D2D3 region of LSU of the rDNA and mitochondrial cytochrome oxidase I gene. Two variants of the ITS sequence were observed in the strain CS42, which had either C (40\%) or T $(60 \%)$ base at a position, which corresponded to position $335 \mathrm{bp}$ of the sequence MT835467.1. 
The SSU sequence of $O$. siddiqii was the most similar to those of O. myriophilus Poinar, 1986 (approximately 89-90\%) and O. safricanus Serepa-Dlamini \& Gray 2018 (name amended from O. safricana) (98.7\%) (Table 4). In the ITS region, the highest similarities between the O. siddiqii sequences were observed with O. citri Tabassum, Shahina, Nasira and Erum, 2016 (81.5\%); O. myriophilus (80.4\%); and O. chongmingensis Zhang, Liu, Xu, Sun, Yang, An, Gao, Lin, Lai, He, Wu \& Zhang, 2008 (79.9\%) (Table 5).

Table 4. Pairwise distances of the SSU region of the $r D N A$ among species of the "insectivorus" group of the genus Oscheius. The values above the diagonal represent percent similarities, and values below the diagonal represent numbers of character differences.

\begin{tabular}{|c|c|c|c|c|c|c|c|c|c|c|c|c|c|c|c|c|c|}
\hline S. No. & SSU Region & 1 & 2 & 3 & 4 & 5 & 6 & 7 & 8 & 9 & 10 & 11 & 12 & 13 & 14 & 15 & 16 \\
\hline 1 & U81588 O. myriophilus & & 99.8 & 100 & 99.8 & 96.0 & 99.9 & 99.6 & 96.9 & 97.1 & 96.8 & 96.7 & 98.9 & 97.5 & 97.7 & 97.0 & 96.4 \\
\hline 2 & KP756941 O. myriophilus & 3 & & 99.7 & 99.6 & 95.8 & 99.8 & 99.3 & 96.7 & 96.9 & 96.7 & 96.5 & 98.7 & 97.3 & 97.5 & 96.8 & 96.2 \\
\hline 3 & MW430436.1 O. myriophilus & 0 & 3 & & 100 & 98.2 & 99.9 & 99.7 & 96.8 & 96.8 & 96.8 & 96.7 & 99.0 & 97.2 & 98.5 & 97.1 & 97.9 \\
\hline 4 & U13936 O. myriophilus & 3 & 6 & 0 & & 95.9 & 99.8 & 99.6 & 96.8 & 96.9 & 96.7 & 96.6 & 98.8 & 97.4 & 97.6 & 96.9 & 96.3 \\
\hline 5 & KT825913 O. microvilli & 63 & 66 & 17 & 65 & & 95.9 & 97.8 & 93.7 & 94.7 & 93.7 & 93.7 & 96.0 & 93.9 & 93.9 & 94.7 & 93.1 \\
\hline 6 & AF082994 O. myriophilus & 1 & 4 & 1 & 4 & 64 & & 99.6 & 96.8 & 97.0 & 96.8 & 96.7 & 98.9 & 97.5 & 97.7 & 97.0 & 96.4 \\
\hline 7 & KM270115 O. safricanus & 4 & 7 & 2 & 4 & 22 & 4 & & 96.3 & 96.3 & 96.2 & 96.2 & 98.7 & 96.9 & 97.0 & 96.6 & 96.9 \\
\hline 8 & MT548590 O. chongmingensis & 51 & 54 & 30 & 53 & 98 & 52 & 37 & & 99.9 & 99.9 & 99.9 & 96.4 & 96.5 & 96.2 & 98.3 & 95.9 \\
\hline 9 & EF503692 O. chongmingensis & 45 & 48 & 30 & 47 & 82 & 46 & 37 & 1 & & 100 & 99.9 & 96.7 & 96.5 & 96.3 & 98.4 & 95.9 \\
\hline 10 & EU273597 O. chongmingensis & 53 & 56 & 30 & 55 & 99 & 54 & 38 & 1 & 0 & & 99.9 & 96.3 & 96.3 & 95.9 & 98.3 & 95.8 \\
\hline 11 & JQ002566 O. rugaoensis & 52 & 55 & 31 & 54 & 99 & 53 & 38 & 1 & 2 & 2 & & 96.3 & 96.3 & 96.0 & 98.3 & 95.7 \\
\hline 12 & MT835468 O. siddiqii CS42 & 16 & 19 & 9 & 18 & 60 & 17 & 12 & 55 & 49 & 56 & 56 & & 98.0 & 98.3 & 97.1 & 97.0 \\
\hline 13 & C. & 42 & 45 & 26 & 43 & 96 & 43 & 31 & 58 & 54 & 64 & 59 & 30 & & 97.0 & 96.8 & 96.4 \\
\hline 14 & AY75 & 38 & 41 & 14 & 40 & 95 & 39 & 30 & 63 & 57 & 69 & 64 & 26 & 50 & & 96.6 & 96.8 \\
\hline 15 & MK932670 O. citri WGN & 46 & 49 & 27 & 48 & 81 & 47 & 33 & 26 & 24 & 27 & 27 & 44 & 50 & 52 & & 96.1 \\
\hline 16 & FJ547240 O. carolinensis & 60 & 63 & 20 & 62 & 108 & 61 & 31 & 68 & 63 & 71 & 69 & 46 & 60 & 53 & 60 & \\
\hline
\end{tabular}

Table 5. Pairwise distances of the ITS region of the rDNA among species of the "insectivorus" group of the genus Oscheius. Values above the diagonal represent percent similarities, and values below the diagonal present numbers of character differences.

\begin{tabular}{|c|c|c|c|c|c|c|c|c|c|c|c|c|c|c|c|c|c|c|c|c|}
\hline $\begin{array}{c}\text { S. } \\
\text { No. }\end{array}$ & ITS Region & 1 & 2 & 3 & 4 & 5 & 6 & 7 & 8 & 9 & 10 & 11 & 12 & 13 & 14 & 15 & 16 & 17 & 18 & 19 \\
\hline 1 & MG742117 O. myriophilus & & 97.6 & 99.4 & 99.3 & 99.4 & 85.7 & 89.2 & 73.2 & 74.6 & 75.4 & 73.8 & 64.9 & 75.6 & 76.7 & 79.7 & 78.8 & 73.1 & 86.5 & 70.0 \\
\hline 2 & MG742121 O. myriophilus & 23 & & 97.6 & 97.6 & 98.2 & 84.4 & 88.6 & 73.9 & 74.1 & 74.9 & 74.1 & 64.1 & 75.7 & 76.1 & 79.9 & 79.7 & 72.3 & 85.3 & 69.4 \\
\hline 3 & KT825914 O. microvilli & 6 & 23 & & 99.3 & 99.5 & 85.7 & 89.3 & 74.2 & 74.8 & 75.6 & 74.1 & 64.9 & 76.1 & 76.7 & 80.1 & 79.5 & 72.8 & 86.5 & 69.8 \\
\hline 4 & KP792651 O. myriophilus & 7 & 24 & 7 & & 98.9 & 85.4 & 88.8 & 74.1 & 74.8 & 75.6 & 74.5 & 64.6 & 76.4 & 76.5 & 80.4 & 79.6 & 72.8 & 86.2 & 69.9 \\
\hline 5 & MF372144 O. myriophilus & 5 & 15 & 4 & 9 & & 85.8 & 90.6 & 72.7 & 72.8 & 72.9 & 72.6 & 65.6 & 72.8 & 76.9 & 77.6 & 77.7 & 72.6 & 86.3 & 68.7 \\
\hline 6 & KF684370 O. safricanus & 115 & 125 & 115 & 117 & 112 & & 83.8 & 72.4 & 72.6 & 72.7 & 72.4 & 67.3 & 73.3 & 76.9 & 77.7 & 77.7 & 74.1 & 98.5 & 67.6 \\
\hline 7 & KM492926 O. basothovii & 86 & 91 & 85 & 89 & 73 & 122 & & 72.2 & 72.3 & 72.4 & 72.2 & 66.7 & 72.9 & 75.5 & 74.7 & 74.8 & 72.5 & 84.1 & 69.7 \\
\hline 8 & MT548591 O. chongmingensis & 260 & 247 & 245 & 250 & 216 & 217 & 214 & & 98.2 & 98.6 & 98.1 & 76.0 & 88.8 & 77.4 & 79.5 & 79.9 & 93.3 & 74.1 & 69.1 \\
\hline 9 & EU273598 O. chongmingensis & 238 & 244 & 237 & 237 & 215 & 215 & 213 & 18 & & 99.9 & 98.7 & 76.3 & 89.4 & 77.1 & 79.0 & 79.0 & 93.7 & 74.3 & 68.5 \\
\hline 10 & EF503690 O. chongmingensis & 228 & 234 & 227 & 227 & 214 & 214 & 212 & 14 & 1 & & 99.1 & 76.4 & 89.5 & 77.2 & 79.2 & 79.2 & 93.8 & 74.4 & 68.9 \\
\hline 11 & JQ002565 O. rugaoensis & 248 & 248 & 246 & 247 & 217 & 217 & 214 & 20 & 13 & 9 & & 76.2 & 89.2 & 76.9 & 79.3 & 79.5 & 93.6 & 74.0 & 68.8 \\
\hline 12 & MN635765 Oscheius sp. & 285 & 291 & 285 & 287 & 273 & 262 & 251 & 205 & 202 & 201 & 202 & & 84.6 & 70.6 & 69.4 & 69.5 & 78.3 & 67.5 & 62.3 \\
\hline 13 & MN137988.2 O. citri & 229 & 236 & 226 & 228 & 220 & 214 & 213 & 111 & 105 & 104 & 108 & 135 & & 79.1 & 81.4 & 81.5 & 89.9 & 74.9 & 70.0 \\
\hline 14 & MK277315 Oscheius sp. & 175 & 179 & 175 & 176 & 170 & 165 & 181 & 176 & 178 & 177 & 180 & 222 & 164 & & 99.6 & 99.7 & 77.9 & 77.9 & 69.3 \\
\hline 15 & MT835467 O. siddiqii CS42 & 187 & 191 & 184 & 185 & 173 & 171 & 190 & 196 & 200 & 196 & 200 & 248 & 180 & 3 & & 99.9 & 77.5 & 78.8 & 72.9 \\
\hline 16 & MH837095.2 O. siddiqii CS42 & 199 & 193 & 191 & 197 & 172 & 171 & 189 & 196 & 200 & 196 & 200 & 247 & 179 & 2 & 1 & & 77.6 & 78.8 & 73.4 \\
\hline 17 & MF441494 O. indicus & 217 & 223 & 219 & 219 & 214 & 200 & 207 & 57 & 53 & 52 & 54 & 178 & 86 & 171 & 185 & 184 & & 75.4 & 66.4 \\
\hline 18 & LN611142 Oscheius sp. & 113 & 123 & 113 & 115 & 111 & 12 & 125 & 212 & 210 & 209 & 212 & 262 & 209 & 165 & 169 & 169 & 198 & & 69.1 \\
\hline 19 & FJ547241 O. carolinensis & 290 & 293 & 290 & 291 & 256 & 263 & 237 & 309 & 309 & 302 & 309 & 325 & 294 & 238 & 254 & 253 & 282 & 259 & \\
\hline
\end{tabular}

The analysis of the cytochrome oxidase I gene showed that the sequence of $O$. siddiqii differs from other available species from the "insectivorus" group by 3-9\%, with O. chongmingensis being the most similar $(97.3 \%)$.

All of the phylogenetic analyses show that $O$. siddiqii is a sister taxon of the group consisting of O. myriophilus; O. safricanus; O. microvilli Zhou, Yang, Wang, Bao, Wang, Hou, Lin, Yedid \& Zhang, 2017; and several unidentified Oscheius species (Figures 5-7). Interestingly, the ITS tree shows $O$. siddiqii CS42 forming a highly supported monophyletic 
clade with Oscheius sp. (MK277315), which was also collected from India, their sequences being almost identical (similarity over $99.1 \%$ ); these nematodes are most likely conspecific.

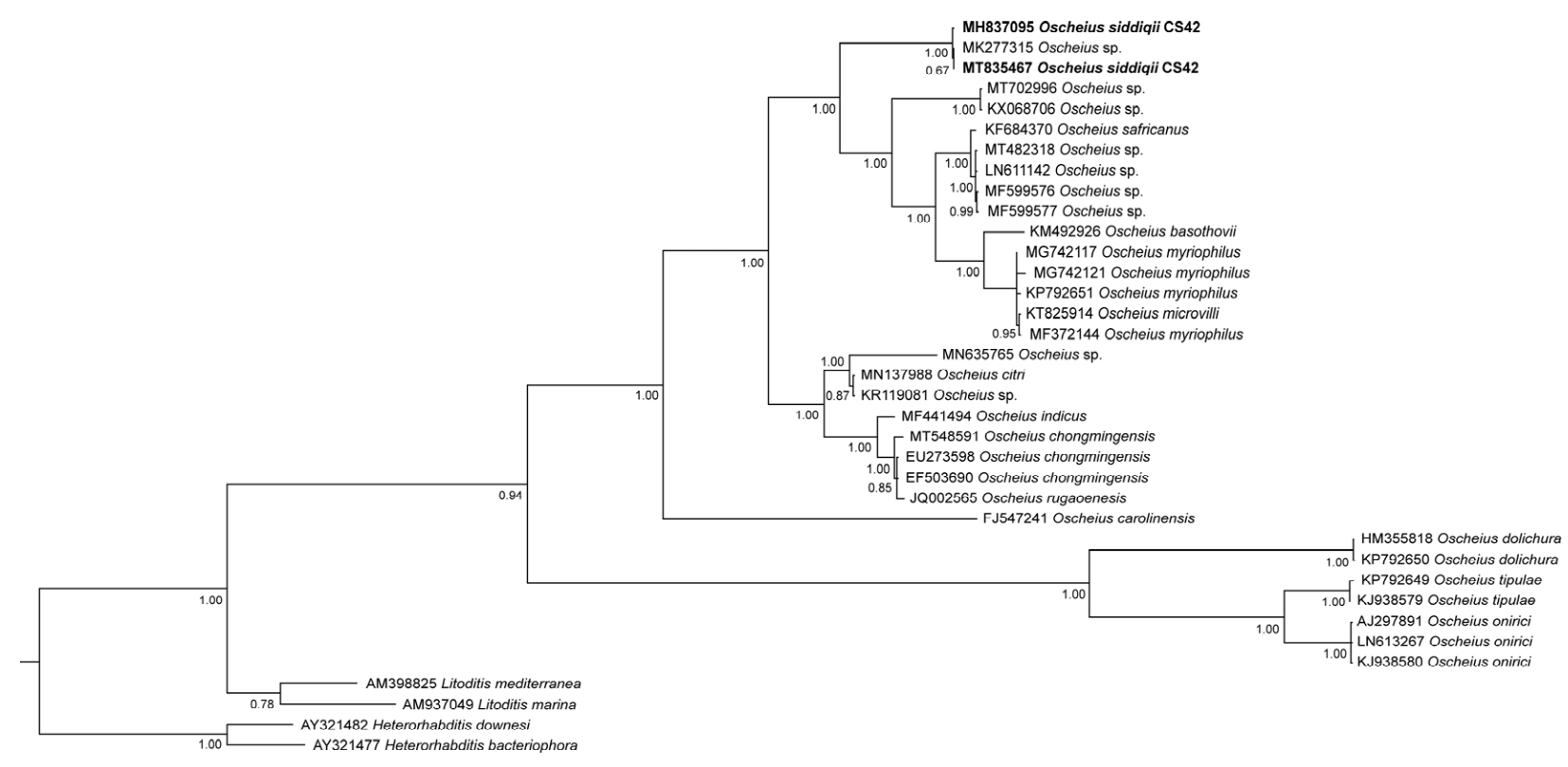

Figure 5. Phylogenetic relationships of Oscheius siddiqii and other Oscheius species as inferred from Bayesian analysis of sequences of the internal transcribed spacer (ITS1-5.8S-ITS2) rDNA segment. Bayesian posterior probabilities (\%) higher or equal to $60 \%$ are provided at each node. The scale bar indicates the number of substitutions per site.

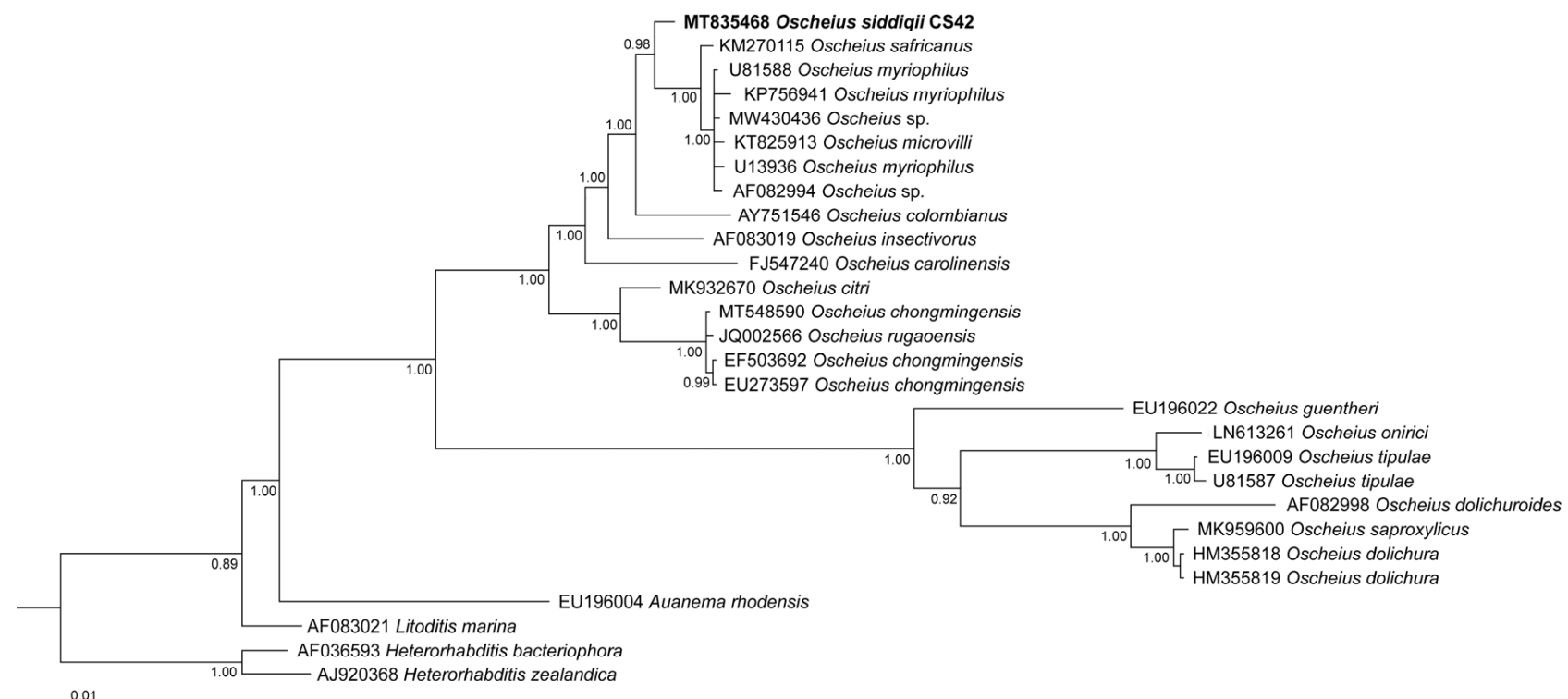

Figure 6. Phylogenetic relationships of Oscheius siddiqii and other Oscheius species as inferred from Bayesian analysis of sequences of the small subunit (18S) of the rDNA segment. Bayesian posterior probabilities (\%) that are higher than or equal to $60 \%$ are provided at each node. The scale bar indicates the number of substitutions per site. 


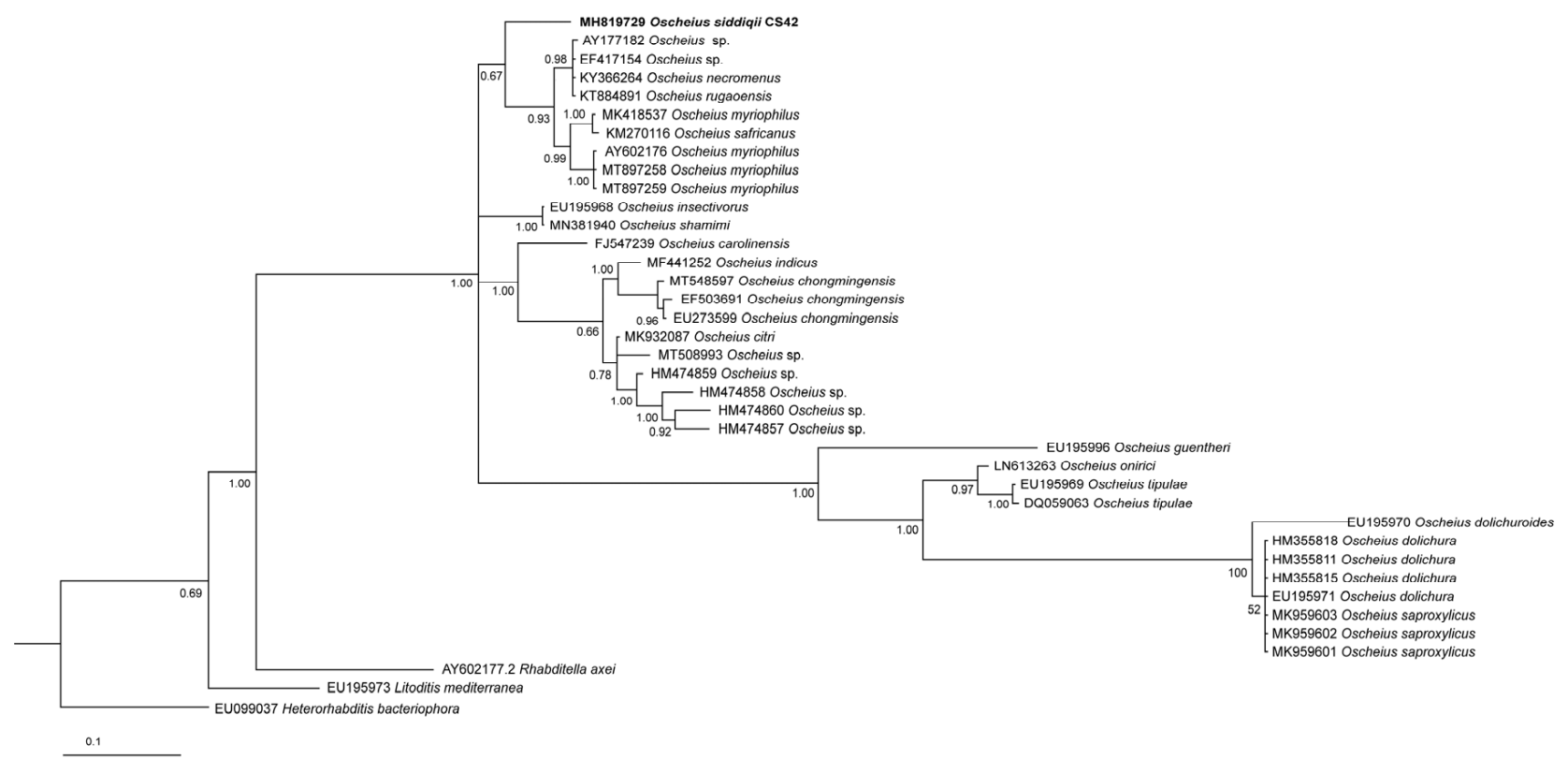

Figure 7. Phylogenetic relationships of Oscheius siddiqii and other Oscheius species as inferred from Bayesian analysis of sequences of the D2-D3 fragments of large subunit (28S) of rDNA region. Bayesian posterior probabilities (\%) higher than or equal to $60 \%$ are provided at each node. The scale bar indicates the number of substitutions per site.

\section{Discussion}

\subsection{Remarks}

Unfortunately, some of the currently recognized Oscheius species have inadequate or no molecular support. This is because at present, since predominantly molecular identification of nematodes is used, the lack of molecular data for nematode species complicates the systematics of the group.

Generally, the species with no molecular data not only complicate systematic and phylogenetic studies but also present a problem for biodiversity studies, and it is thus desirable to match these older taxa with molecular data. This, however, presents a challenge, especially in the case of nematodes, where a number of cryptic species have been reported [39-41], and therefore, assigning the molecular data just based on morphological similarities poses an inherent risk of overlooking cryptic species. Nevertheless, such a situation can be possibly mended in the future if the original species is re-isolated. Alternatively, there will be more taxa than the actual evolutionary lineages, and according to Carstens et al. [42], in most contexts, it is better to fail to delimit species than it is to falsely delimit entities that do not represent actual evolutionary lineages. Moreover, Oscheius species, for which both morphology and molecular data are available, show interspecific differences in both datasets, and so far, no cryptic species have been reported in this group.

The material examined now from India agrees well with O. siddiqii and O. niazii Tabassum \& Shahina, 2010 (the correct name of the latter should be O. niazensis because it refers to a village), the two very similar species that were both described from the same district in Pakistan. Regrettably, we were not able to gain the access to paratypes of these Pakistani taxa in order to study their morphology and to corroborate their identity despite numerous attempts. The descriptions of the type populations of both Pakistani species, despite the poor quality of their illustrations and the existence of some inaccuracies in the drawings, show negligible morphological and morphometrical differences (see Supplementary Tables S2 and S3), and the measurements mainly overlap, with O. niazensis having somewhat larger ranges.

Therefore, with no significant morphological difference between both nematodes, we consider them to be two populations of a single species. Alternatively, the Pakistani and Indian populations could represent two morphologically identical species; however, we 
consider this possibility to be unlikely. Comparisons of the Indian populations examined now with both Pakistani species have shown that they resemble each other in terms of all of the important traits, such as stoma morphology (especially in O. niazensis), the arrangement of the genital papillae, with the GP2 and GP3 being spaced closer together, and the spicules, with the ventral bent tip, with no other important differences being detected. Unfortunately, the Pakistani species lack molecular data in order to adequately compare them to the Indian populations. Nevertheless, the morphological and morphometrical data show that the Indian populations and both Pakistani populations are the same species. According to the International Code of Zoological Nomenclature (ICZN), O. siddiqii, being the first described species in the paper published by Tabassum \& Shahina [16], is the valid name for the taxon and the type population, whereas $O$. niazensis should be considered as its junior synonym.

For the first time, we provide the COI sequences for five Oscheius species, and these data will form the basis for further molecular systematic studies of the group. The sequence diversity among species was lower than it was in the ITS sequences, which is in agreement with the observations made with, e.g., heterorhabditid entomopathogenic nematodes [43] or populations of the parasitic nematode Camallanus cotti [44]. Nevertheless, the COI sequences show both interspecific and intraspecific variation and thus provide further resolution among Oscheius species.

\subsection{Diagnosis (Based on Indian Populations)}

Oscheius siddiqii is characterized by its body size, which ranges from $1.10-1.70 \mathrm{~mm}$ in females and from $0.92-1.44 \mathrm{~mm}$ in males; a cuticle with delicate transverse striations; lateral fields consisting of eight prominent lines; a lip region bearing six separate lips; a tubular stoma that is 13-20 $\mu \mathrm{m}$ in length; a pharynx with a more robust and subcylindrical metacorpus; a nerve ring at the isthmus-bulb junction; an excretory pore situated at the level of the basal pharyngeal bulb or slightly posterior; a didelphic-amphidelphic female reproductive system ; an equatorial vulva $(\mathrm{V}=45-57)$ with a lateral epiptygmata; a rectum that is 1.9-2.8 times the anal body width; a female conical tail with an acute tip (123-180 $\mu \mathrm{m}$ long, $\left.c=7.8-15.4, c^{\prime}=3.5-7.5\right)$ and a male conoid tail (36-49 $\mu \mathrm{m}$ long, $\left.c=20.0-33.0, c^{\prime}=1.4-2.5\right)$ with small filiform part, spicules 39-55 $\mu \mathrm{m}$ long with a crochetlike tip; and a gubernaculum that is $21-26 \mu \mathrm{m}$ long. A bursa leptoderan with nine pairs of genital papillae (GP) $(1+1+1 / 3+3+$ ph) and well developed phasmids are located posteriorly to GP9.

\subsection{Phylogenetic Relationships of the Species of the Subgenus Oscheius}

The reliable reconstruction of phylogenetic relationships within the subgenus Oscheius is hampered by the fact that for some established species, not all standardly used genetic markers are available. This not only complicates phylogenetic reconstructions of the relationship within the group but also presents a challenge for distinguishing the newly described species from the existing ones. In our analyses, the position of the majority of Oscheius species was consistent in all trees, and the majority of species were clearly separated from other species, with four prominent exceptions: Oscheius basothovii Lephoto \& Gray, 2019; O. safricanus, O. rugaoensis Zhang, Liu, Tan, Wang, Qiao, Yedid, Dai, Qiu, Yan, Tan, Su, Lai \& Gao, 2012; and O. microvilli (Figures 5-7). Below, we revise the available molecular and morphological data of these taxa. In the D2D3 tree, the sequence attributed to the O. shamimi Tahseen \& Nisa, 2006 (MN381940) groups with O. insectivorus (Körner, 1954) Andrássy, 1976 (EU195968) with 100\% support, and both sequences are almost identical, with only one bp deletion difference. The D2D3 region is known to provide little resolution, and identical D2D3 sequences were observed in some closely related Meloidogyne species [45]. However, considering the fact that intraspecific differences in Oscheius species with more available D2D3 sequences (O. Myriophilus, O. chongmingensis) are significantly higher and range up to $13 \mathrm{bp}$, we assume that most likely, the sequence MN381940 actually belongs to O. insectivorus. 


\subsubsection{Oscheius basothovii and O. safricanus}

Based on the analyses of the ITS and SSU sequences, Oscheius safricanus seems to be very closely related to O. myriophilus, and in the LSU tree, it falls within O. myriophilus strains. Unfortunately, it is not possible to compare the morphology because the line illustration provided by Serepa-Dlamini \& Gray [46] is slightly modified from that of the description of Oscheius rugaoensis provided by Zhang et al. [47], and surprisingly, the LM micrographs, at least in the male (see Figure 3B), apparently correspond with some species of the genus Steinernema. According to the morphology of the spicules.

Interestingly, the ITS tree shows that Oscheius basothovii is even closer to O. myriophilus, with which it forms a monophyletic clade that is sister to O. safricanus. Unfortunately, no LSU and SSU sequences have been given in the description of O. basothovii [48], so it is not possible to assess the status of this species. Morphologically, the very poor quality of the illustrations provided for O. basothovii by Lephoto \& Gray [48] makes it impossible to correctly evaluate its morphology and to compare it with O. myriophilus.

Both species, O. basothovii and O. safricanus, could be considered as species inquirendae.

\subsubsection{Oscheius microvilli}

The original description of O. microvilli only provides the ITS and SSU sequences under accession numbers KT825914 and KT825913, respectively [49]. In both of our phylogenetic reconstructions, $O$ microvilli falls into the clade of other $O$. myriophilus strains with high support.

Furthermore, the differences between the ITS sequence attributed to O. microvilli and the respective sequences of other O. myriophilus are negligible and are within the standard intraspecific range (Table 5). In the case of SSU, the analysis revealed more than 60 differences (Table 4). The fact that the conservative SSU harbors several times more differences than the variable ITS suggests that the SSU sequence might be inadequately edited. A closer look at the alignment shows that all of the differences occur at the beginning (1-41 bp) and at the end (1572-1615 bp) of the sequence and in positions 1209-1332 bp. In all of the other positions, the sequence is identical to the sequences of the O. myriophilus strains. The corresponding positions of the alignment are quite conservative, and these variable positions in the sequence KT825913 are probably sequencing errors. To conclude, the available molecular data attributed to O. microvilli are not sufficient to separate this taxon from O. myriophilus. Morphological comparisons of these two species do not display significant differences, with the exception of males, but the male morphology described in the description of O. microvilli agrees with Caenorhabditis sinica according the bursa morphology among other morphological characteristics and morphometry (see [4]). Therefore, O. microvilli is proposed as a junior synonym of O. myriophilus.

\subsubsection{Oscheius rugaoensis}

The original description of O. rugaoensis provided the ITS and SSU sequences [47], and in both the ITS and SSU trees, this species is a member of a monophyletic clade together with several strains of $O$. chongmingensis, suggesting that these nematodes are in fact conspecific. Moreover, distance analyses of the ITS and SSU sequences of O. rugaoensis and $O$. chongmingensis only show an insignificant number of differences (Tables 4 and 5). The NCBI GenBank database contains one D2D3 sequence attributed to O. rugaoensis (KT884891) that is, however, almost identical to the sequence attributed to O. necromenus (Sudhaus \& Schulte, 1989), and in the LSU tree, their position strongly differs from the position of $O$. rugaoensis in both ITS and SSU trees. This sequence thus probably belongs to $O$. necromenus. In general, the available molecular data fail to support O. rugaoensis as a separate species from $O$. chongmingensis. Morphologically, O. rugaoensis shows a resemblance to O. chongmingensis, mainly in the morphology of the stoma, the position of the excretory pore and nerve ring, the morphology of both the female and male tails and spicules, the presence of pseudopeloderan type bursa, and the presence of small bristle-like sensilla posterior to the cloacal opening. Morphometrically, the also show 
close similitude to each other, such as in the size of the females; similar ratios $(a, b, c$, and $\mathrm{c}^{\prime}$ ); similar anal body width; similar SW\%, GS\% and V\%; and other morphometric measurements (Supplementary Tables S2 and S3). Therefore, O. rugaoensis is proposed as a junior synonym of $O$. chongmingensis, while the population from Japan [50] attributed to O. rugaoensis should be considered conspecific with the population of $O$. necromenus that is described from Iran [51].

\section{Conclusions}

Potentially entomopathogenic nematodes of the genus Oscheius have been the subject of increased scientific interest in recent years. However, the research is complicated by unclear taxonomy, with some of the species being poorly described and having inadequate or no molecular support. In our study, we provide a morphological and molecular characterization of Oscheius siddiqii and propose O. niazensis as its junior synonym.

Using the available molecular data and newly sequenced COI gene of five Oscheius, we revised other species belonging to the genus Oscheius and discuss species delimitation. Our results show that a majority of Oscheius with the available molecular support are well characterized by the combination of traditional rDNA genes (ITS, LSU and SSU) but that the COI sequence provides further resolution among Oscheius species. Based on morphological and molecular data, we propose $O$. microvilii and O. rugaoensis as junior synonyms of $O$. myriophilus and $O$. chongmingensis, respectively. Furthermore, O. basothovii and $O$. safricanus should be considered as species inquirendae. Our results highlight the importance of the proper molecular characterisation of newly described Oscheius species. Therefore, any future species description should provide all three standardly used rDNA markers (ITS, SSU, and LSU) in combination with at least one mitochondrial COI gene.

Supplementary Materials: The following are available online at https:/ /www.mdpi.com/article/10 $.3390 /$ biology10121239/s1, Table S1: Diagnosis of the genus and list of species, Table S2: Comparative morphometrics of the females of the species of the subgenus Oscheius. All measurements in $\mu \mathrm{m}$ except for the indexes, Table S3: Comparative morphometrics of the males of the species of the subgenus Oscheius. All measurements in $\mu \mathrm{m}$ except for the indexes.

Author Contributions: Conceptualization, A.H.B., J.A. and V.P.; methodology, A.H.B., J.A. and V.P.; software, A.H.B. and V.P.; validation, A.H.B., J.A. and V.P.; formal analysis, A.H.B., J.A. and V.P.; investigation, A.H.B., S.G. and A.R.; resources, A.H.B. and A.R.; data curation, A.H.B., S.G., A.R. and A.K.C.; writing - original draft preparation, A.H.B.; writing-review and editing, J.A. and V.P.; visualization, A.H.B., J.A. and V.P.; supervision, A.H.B., J.A. and V.P.; project administration, A.H.B. and J.A.; funding acquisition, A.H.B., J.A. and V.P. All authors have read and agreed to the published version of the manuscript.

Funding: The work of Aashaq Hussain Bhat is supported by a Postdoctoral Swiss Government Excellence Scholarship (Grant Nr. 2021.0463 to A.H.B.). The work of Aasha Rana was funded by Department of Science and Technology (DST), New Delhi, India, through a DST WOS-A (SR/WOS-A/LS1083/2014) (Aasha Rana). The research was further supported by University of Jaén, Spain, Research Support Plans "PAIUJA 2019/2020: EI_RNM02_2019" and "PAIUJA 2021/2022: EI_RNM02_2021". The research also received institutional support RVO: 60077344 (Institute of Entomology, BC CAS).

Institutional Review Board Statement: Not applicable.

Informed Consent Statement: Not applicable.

Data Availability Statement: Not applicable.

Acknowledgments: The authors are grateful to the head of the Department of Zoology, Chaudhary Charan Singh University, for providing the necessary laboratory equipment. Scanning electron microscopic images were taken with the help of technical staff (Amparo Martínez- Morales) and the facilities of the "Centro de Instrumentación Científico-Técnica (CICT)", University of Jaén.

Conflicts of Interest: The authors declare no conflict of interest. The funders had no role in the design of the study; in the collection, analyses, or interpretation of data; in the writing of the manuscript; or in the decision to publish the results. 


\section{References}

1. Andrássy, I. Evolution as a Basis for the Systematization of Nematodes; Pitman Publishing Ltd.: London, UK, 1976.

2. Sudhaus, W. Vergleichende Untersuchungen zur Phylogenie, Systematik, Ökologie, Biologie und Ethologie der Rhabditidae (Nematoda); Schweizerbart Science Publishers: Stuttgart, Germany, 1976.

3. Sudhaus, W. Phylogenetic systematisation and catalogue of paraphyletic "Rhabditidae" (Secernentea, Nematoda). J. Nematode Morphol. Syst. 2011, 14, 113-178.

4. Abolafia, J.; Peña-Santiago, R. Morphological and molecular characterization of Oscheius saproxylicus sp. n. (Rhabditida, Rhabditidae) from decaying wood in Spain, with new insights into the phylogeny of the genus and a revision of its taxonomy. J. Nematol. 2019, 51, e2019-53. [CrossRef] [PubMed]

5. Andrássy, I. A Taxonomic Review of the Suborder Rhabditina (Nematoda: Secernentia); ORSTOM: Paris, France, 1983.

6. Andrássy, I. Free-Living Nematodes of Hungary: Nematoda Errantia; Hungarian Natural History Museum: Budapest, Hungary, 2005; Volume 1.

7. Rana, A.; Bhat, A.; Chaubey, A.; Půža, V.; Abolafia, J. Redescription and synonymization of Oscheius citri Tabassum, Shahina, Nasira and Erum, 2016 (Rhabditida, Rhabditidae) from India and its taxonomical consequences. J. Helminthol. 2021, 95, e24. [CrossRef]

8. Adams, B.J.; Dillman, A.R.; Finlinson, C. Molecular taxonomy and phylogeny. In Root-Knot Nematodes; CABI: Egham, UK, 2009; pp. 119-138.

9. Landa, B.B.; Rius, J.E.P.; Vovlas, N.; Carneiro, R.M.; Maleita, C.M.; de Abrantes, I.M.; Castillo, P. Molecular characterization of Meloidogyne hispanica (Nematoda, Meloidogynidae) by Phylogenetic analysis of genes within the rDNA in Meloidogyne spp. Plant Dis. 2008, 92, 1104-1110. [CrossRef] [PubMed]

10. Hugall, A.; Stanton, J.; Moritz, C. Reticulate Evolution and the origins of ribosomal internal transcribed spacer diversity in apomictic Meloidogyne. Mol. Biol. Evol. 1999, 16, 157-164. [CrossRef]

11. Půža, V.; Chundelová, D.; Nermut', J.; Žurovcová, M.; Mráček, Z. Intra-individual variability of its regions in entomopathogenic nematodes (Steinernematidae: Nematoda): Implications for their taxonomy. BioControl 2015, 60, 547-554. [CrossRef]

12. Kiewnick, S.; Holterman, M.; van den Elsen, S.; van Megen, H.; Frey, J.E.; Helder, J. Comparison of two short DNA barcoding loci (COI and COII) and two longer ribosomal DNA genes (SSU \& LSU rRNA) for specimen identification among quarantine root-knot nematodes (Meloidogyne spp.) and their close relatives. Eur. J. Plant Pathol. 2014, 140, 97-110.

13. Torrini, G.; Mazza, G.; Carletti, B.; Benvenuti, C.; Roversi, P.F.; Fanelli, E.; De Luca, F.; Troccoli, A.; Tarasco, E. Oscheius onirici sp. n. (Nematoda: Rhabditidae): A new entomopathogenic nematode from an italian cave. Zootaxa 2015, 3937, 533-548. [CrossRef] [PubMed]

14. Foye, S.; Steffan, S.A. A rare, recently discovered nematode, Oscheius onirici (Rhabditida: Rhabditidae), kills Drosophila suzukii (Diptera: Drosophilidae) within fruit. J. Econ. Entomol. 2020, 113, 1047-1051. [CrossRef]

15. Bedding, R.; Akhurst, R. A Simple technique for the detection of insect parasitic rhabditid nematodes in soil. Nematologica 1975, 21, 109-110. [CrossRef]

16. Tabassum, K.; Shahina, F. Oscheius siddiqii and O. niazii, Two new entomopathogenic nematode species from pakistan, with observations on O. shamimi. Int. J. Nematol. 2010, 20, 75-84.

17. Bhat, A.H.; Chaubey, A.K.; Hartmann, J.; Půža, V. Notes on the morphology, bionomics, distribution and efficacy of Steinernema siamkayai (Rhabditida: Steinernematidae) from Western Uttar Pradesh, India. Nematology 2021, 1, 817-836. [CrossRef]

18. Bhat, A.H.; Chaubey, A.K.; Abolafia, J. Morphological and molecular characterisation of Distolabrellus veechi (Rhabditida: Mesorhabditidae) from India. Nematology 2020, 22, 439-452.

19. Bhat, A.H.; Istkhar, A.K.C.; Půža, V.; San-Blas, E. First report and comparative study of Steinernema surkhetense (Rhabditida: Steinernematidae) and its symbiont bacteria from subcontinental india. J. Nematol. 2017, 49, 92-102. [CrossRef] [PubMed]

20. Courtney, W.D.; Polley, D.; Miller, V. TAF, an improved fixative in nematode technique. Plant Dis. Rep. 1955, $39,570-571$.

21. Seinhorst, J. A Rapid method for the transfer of nematodes from fixative to anhydrous glycerin. Nematologica 1959, 4, 67-69. [CrossRef]

22. Poinar, G.O. Entomogenous Nematodes: A Manual and Host List of Insect-Nematode Associations; Brill Archive: Leiden, The Nertherlands, 1975; ISBN 90-04-04240-7.

23. Bhat, A.; Chaubey, A.; Půža, V. The first report of Xenorhabdus indica from Steinernema pakistanense: Co-phylogenetic study suggests co-speciation between $X$. indica and its steinernematid nematodes. J. Helminthol. 2019, 93, 81-90. [CrossRef]

24. Abolafia, J. A low-cost technique to manufacture a container to process meiofauna for scanning electron microscopy. Microsc. Res. Tech. 2015, 78, 771-776. [CrossRef] [PubMed]

25. Vrain, T.; Wakarchuk, D.; Levesque, A.; Hamilton, R. Intraspecific rDNA restriction fragment length polymorphism in the Xiphinema americanum group. Fundam. Appl. Nematol. 1992, 15, 563-573.

26. Nguyen, K.B. Methodology, morphology and identification. In Entomopathogenic Nematodes: Systematics, Phylogeny and Bacterial Symbionts; Brill: Leiden, The Nertherlands, 2007; pp. 59-119, ISBN 90-474-2239-2.

27. Liu, J.; Berry, R.E.; Moldenke, A.F. Phylogenetic relationships of entomopathogenic nematodes (Heterorhabditidae and Steinernematidae) inferred from partial 18s rRNA gene sequences. J. Invertebr. Pathol. 1997, 69, 246-252. [CrossRef]

28. Blaxter, M.L.; De Ley, P.; Garey, J.R.; Liu, L.X.; Scheldeman, P.; Vierstraete, A.; Vanfleteren, J.R.; Mackey, L.Y.; Dorris, M.; Frisse, L.M. A molecular evolutionary framework for the phylum nematoda. Nature 1998, 392, 71-75. [CrossRef] 
29. Mráček, Z.; Půža, V.; Nermut, J. Steinernema poinari sp. n.(Nematoda: Steinernematidae) a new entomopathogenic nematode from the Czech Republic. Zootaxa 2014, 3760, 336-350. [CrossRef] [PubMed]

30. De Ley, P.; Blaxter, M. Systematic position and phylogeny. In The Biology of Nematodes; Taylor \& Francis: Singapore, 2002; pp. 1-30.

31. Bhat, A.H.; Askary, T.H.; Ahmad, M.J.; Chaubey, A.K. Description of Heterorhabditis bacteriophora (Nematoda: Heterorhabditidae) Isolated from hilly areas of Kashmir valley. Egypt. J. Biol. Pest Control 2019, 29, 96. [CrossRef]

32. Altschul, S.F.; Gish, W.; Miller, W.; Myers, E.W.; Lipman, D.J. Basic Local Alignment Search Tool. J. Mol. Biol. 1990, 215, 403-410. [CrossRef]

33. Kumar, S.; Stecher, G.; Tamura, K. MEGA7: Molecular evolutionary genetics analysis version 7.0 for bigger datasets. Mol. Biol. Evol. 2016, 33, 1870-1874. [CrossRef] [PubMed]

34. Hall, T. BioEdit: A User-Friendly Biological Sequence Alignment Editor and Analysis Program for Windows 95/98/NT; ScienceOpen: Berlin, Germany, 1999; Volume 41, pp. 95-98.

35. Ronquist, F.; Teslenko, M.; Van Der Mark, P.; Ayres, D.L.; Darling, A.; Höhna, S.; Larget, B.; Liu, L.; Suchard, M.A.; Huelsenbeck, J.P. MrBayes 3.2: Efficient bayesian phylogenetic inference and model choice across a large model space. Syst. Biol. 2012, 61, 539-542.

36. Nylander, J. MrModeltest 2.0; Program Distributed by the Author; Department of Systematic Zoology, Evolutionary Biology Centre, Uppsala University: Uppsala, Sweden, 2004.

37. Maddison, W.; Maddison, D. Mesquite, version 3.51; A Modular System for Evolutionary Analysis. 2018; Chelsea Green Publishing: Chelsea, VT, USA, 2019.

38. Folmer, O.; Black, M.; Hoeh, W.; Lutz, R.; Vrijenhoek, R. DNA primers for amplification of mitochondrial cytochrome c oxidase subunit i from diverse metazoan invertebrates. Mol. Mar. Biol. Biotechnol. 1994, 3, 294-299.

39. Sudhaus, W.; Kiontke, K. Comparison of the cryptic nematode species Caenorhabditis brenneri sp. n. and C. remanei (Nematoda: Rhabditidae) with the stem species pattern of the Caenorhabditis elegans group. Zootaxa 2007, 1456, 45-62. [CrossRef]

40. Kanzaki, N.; Ragsdale, E.J.; Herrmann, M.; Mayer, W.E.; Sommer, R.J. Description of three Pristionchus species (Nematoda: Diplogastridae) from Japan that form a cryptic species complex with the model organism P. pacificus. Zoolog. Sci. 2012, 29 , 403-417. [CrossRef]

41. Palomares-Rius, J.E.; Cantalapiedra-Navarrete, C.; Castillo, P. Cryptic species in plant-parasitic nematodes. Nematology 2014, 16, 1105-1118. [CrossRef]

42. Carstens, B.C.; Pelletier, T.A.; Reid, N.M.; Satler, J.D. How to fail at species delimitation. Mol. Ecol. 2013, 22, 4369-4383. [CrossRef] [PubMed]

43. Dhakal, M.; Nguyen, K.B.; Hunt, D.J.; Ehlers, R.-U.; Spiridonov, S.E.; Subbotin, S.A. Molecular identification, phylogeny and phylogeography of the entomopathogenic nematodes of the genus Heterorhabditis Poinar, 1976: A multigene approach. Nematology 2020, 1, 451-466. [CrossRef]

44. Wu, S.G.; Wang, G.T.; Xi, B.W.; Xiong, F.; Liu, T.; Nie, P. Population genetic structure of the parasitic nematode Camallanus cotti inferred from DNA sequences of ITS1 rDNA and the mitochondrial COI gene. Vet. Parasitol. 2009, 164, 248-256. [CrossRef] [PubMed]

45. Rashidifard, M.; Marais, M.; Daneel, M.S.; Mienie, C.M.; Fourie, H. Molecular characterisation of Meloidogyne enterolobii and other Meloidogyne spp. from South Africa. Trop. Plant Pathol. 2019, 44, 213-224. [CrossRef]

46. Serepa-Dlamini, M.H.; Gray, V.M. A new species of entomopathogenic nematode Oscheius safricana n. sp. (Nematoda: Rhabditidae) from South Africa. Arch. Phytopathol. Plant Prot. 2018, 51, 309-321. [CrossRef]

47. Zhang, K.Y.; Liu, X.H.; Tan, J.; Wang, Y.; Qiao, L.; Yedid, G.; Dai, C.S.; Qiu, R.L.; Yan, X.W.; Tan, H.W. Heterorhabditidoides rugaoensis n. sp. (Rhabditida: Rhabditidae), a novel highly pathogenic entomopathogenic nematode member of Rhabditidae. J. Nematol. 2012, 44, 348 .

48. Lephoto, T.E.; Gray, V.M. Oscheius basothovii n. sp. (Nematoda: Rhabditidae), a new entomopathogenic ematode isolated from an uncultivated grassland in South Africa. Arch. Phytopathol. Plant Prot. 2019, 52, 125-140. [CrossRef]

49. Zhou, G.; Yang, H.; Wang, F.; Bao, H.; Wang, G.; Hou, X.; Lin, J.; Yedid, G.; Zhang, K. Oscheius microvilli n. sp. (Nematoda: Rhabditidae): A facultatively pathogenic nematode from Chongming Island, China. J. Nematol. 2017, 49, 33. [CrossRef]

50. Carta, L.; Thomas, W.; Meyer-Rochow, V. Two nematodes (Nematoda: Diplogastridae, Rhabditidae) from the invasive millipede Chamberlinius hualienensis Wang, 1956 (Diplopoda, Paradoxosomatidae) on Hachijojima Island in Japan. J. Nematol. 2018, 50, 479. [CrossRef]

51. Valizadeh, A.; Goldasteh, S.; Rafiei-Karahroodi, Z.; Pedram, M. The occurrence of three species of the genus Oscheius Andrássy, 1976 (Nematoda: Rhabditida) in Iran. J. Plant Prot. Res. 2017, 57, 248-255. [CrossRef] 